\title{
Complutum
}

ISSN: 1131-6993

\section{Los cuchillos de hierro de la necrópolis protohistórica del Calvari del Molar (Priorat, Tarragona): una revisión}

\author{
Núria Rafel ${ }^{1}$, Xosé-Lois Armada ${ }^{2}$
}

Recibido: 27/04/21 / Aceptado: 02/06/2021

Resumen: Este artículo ofrece una revisión de los cuchillos de hierro recuperados en la necrópolis del Calvari (El Molar, Tarragona) en el curso de las excavaciones realizadas por Salvador Vilaseca en 1930. La obtención de nueva documentación gráfica y la revisión de paralelos ponen de manifiesto que se trata en todos los casos de instrumentos de corte de dorso recto y un solo filo. Al mismo tiempo, la revisión de los contextos locales y regionales apunta a una cronología para los ejemplares más antiguos de finales del s. VIII - inicios del VII ane, anterior a la sugerida hasta la fecha. Los cuchillos de hierro aparecen en la necrópolis del Calvari como únicos elementos de ajuar en sus respectivas tumbas, situadas todas ellas en una posición relativamente periférica en la necrópolis. Estos datos, considerados en su conjunto, permiten una reevaluación del significado social de estos objetos, así como una matización de algunas de las hipótesis presentes en la bibliografía anterior.

Palabras clave: cuchillos de hierro; necrópolis; protohistoria del nordeste peninsular

\section{[en] The iron knives from the protohistoric cemetery of El Calvari del Molar (Priorat, Tarragona): a review}

\begin{abstract}
This article offers a review of the iron knives found in the cemetery of El Calvari (El Molar, Tarragona) during the excavations carried out by Salvador Vilaseca in 1930. The new graphic documentation and a review of iron objects from other sites in the area show that they are all cutting instruments with a straight spine and a single cutting edge. At the same time, a review of the local and regional archaeological contexts suggests that the oldest examples can be dated to the late 8 th - early 7th centuries BC, earlier than previously suggested. The El Calvari iron knives were found as single grave goods in their respective tombs, all of which were in relatively peripheral areas of the cemetery. Taken as a whole, these data allow us to re-evaluate these objects and their social meaning, as well as to nuance of some of the hypotheses previously published in the archaeological literature.
\end{abstract}

Keywords: iron knives, necropolis, protohistory of the northeast of the Iberian Peninsula

Sumario: 1. Introducción. 2. El conjunto arqueológico del Calvari del Molar y su cronología. 3. Las piezas de hierro recuperadas en la necrópolis del Calvari del Molar. 4. ¿Navajas de afeitar o cuchillos? De tipos, funciones y género. 5. Sobre cronologías. 6. Conclusiones. Agradecimientos. Bibliografía.

Cómo citar: Rafel, N.; Armada, X.-L. (2021): Los cuchillos de hierro de la necrópolis protohistórica del Calvari del Molar (Priorat, Tarragona): una revisión. Complutum, 32(1): 73-96.

Profesora jubilada de la Universitat de Lleida, Balmes 350, 4º $1^{\mathrm{a}}$, 08006 Barcelona E-mail: nrafel@historia.udl.cat

2 Instituto de Ciencias del Patrimonio, Consejo Superior de Investigaciones Científicas (Incipit - CSIC). Avda. de Vigo, s/n. 15705 Santiago de Compostela.

E-mail: xose-lois.armada@incipit.csic.es 


\section{Introducción}

En general las piezas férreas de la I Edad del Hierro presentan importantes problemas de conservación. Esto ha redundado en una documentación que en muchos casos es muy insuficiente por la dificultad de identificar las superficies originales a causa de la abundante formación de óxidos e hidróxidos y a tratamientos de laboratorio incompletos o deficientes. Por otra parte, esa intensa corrosión debilita las piezas y como consecuencia de ello aparecen a menudo muy fragmentadas, especialmente en contextos habitacionales. Aunque no es este el único motivo, sin duda ha influido en la confusión que afecta a su identificación funcional y tipológica. Por ello es importante tratar de precisar algo los términos.

Los cuchillos destacan como uno de los primeros elementos de hierro que se documentan en el nordeste peninsular. Desde un punto de vista tipológico han sido clasificados usual, y a veces abusivamente, como pertenecientes al tipo Grand Bassin I o, con menor frecuencia, como navajas de tipo Mailhac. Estas identificaciones en algunos casos deben rechazarse de plano. Los cuchillos característicos de Grand Bassin I (730-580 ane) son piezas de dorso y filo rectos que aproximadamente en el cuarto distal de la hoja presentan un dorso descendente hasta la punta; suelen tener una lengüeta con dos remaches. A diferencia de algunos de los cuchillos que han sido clasificados de manera errónea como del tipo Grand Bassin I, la punta no es descendente, sino que está al mismo nivel que el filo (Fig. 1, 1).

De las 66 tumbas excavadas en el solar de Grand Bassin I no se recuperó ajuar alguno en trece, siendo por lo tanto 53 las que sí lo proporcionaron. De estas últimas más de un $50 \%$ (28 tumbas) contenían hierro, mientras que doce de ellas $(22,6 \%)$ incorporaban cuchillos al ajuar metálico. El resto de objetos de hierro consistía en fíbulas, brazaletes, agujas, cinturones de cadenas, un broche de cinturón, un puñal, unas pinzas y anillos o anillas. Siete de las tumbas $(7,8,17,18,39,54,55)$ contenían dos cuchillos, mientras que el resto $(31,41,48$, $59,64)$ solo uno. Todos los cuchillos contaban con dos remaches, excepto uno de ellos (tumba 8) que tenía solo uno (Louis et al. 1958: vol. 2, 40-42, 49-58). En la fase siguiente, Grand Bassin II (580-430 ane), los cuchillos evolucionan hacia tipos en los que el dorso puede curvarse y la punta suele elevarse, correspondientes a los tipos A4 y A5 de A. Filippini (2007: fig. 3). La publicación de la necrópolis de Le Peyrou en Agde (Nickels 1989), muy posterior, permitió conocer un nuevo elenco de cuchillos de este tipo (49 ejemplares) que se consideran del tipo Grand Bassin I por el autor, aunque algunos de ellos presentan variantes sobre el tipo canónico, siendo significativa en este sentido la presencia de algunos cuchillos de punta ascendente. Nickels clasificó el conjunto en dos grupos, atendiendo únicamente a su tamaño. En el caso, aún más reciente, de Can Piteu-Can Roqueta las puntas ascendentes, junto con otras variables, se consideran variantes del tipo Grand Bassin I (Zamora 2014-2015: 17).

Como veremos más adelante, las identificaciones de cuchillos de hierro del nordeste como navajas tipo Mailhac no tienen base alguna. Por otra parte, existe también una gran confusión en relación a la utilización del término afalcatado, que algunos autores atribuyen a cuchillos de tipología muy diversa (Mancebo 2000), lo que hace que se califique con tal epíteto a cuchillos curvos o cuchillos rectos con punta diferenciada ${ }^{3}$. Nosotros consideraremos cuchillos afalcatados aquellos que presentan una inflexión en la parte medial de la pieza, acogiéndonos a lo definido por Mateos y Sánchez (2014: 138-39). Estos autores ofrecen una completa descripción del cuchillo afalcatado, que tiene como rasgos diferenciales la hoja con el dorso acodado y un filo, por lo general, de forma convexa en su tercio distal, más o menos marcada en función de los ejemplares; la anchura de la hoja se reduce notablemente en la zona central engrosando de nuevo en el tercio proximal, más cerca de la empuñadura (Fig. 1, 2). 

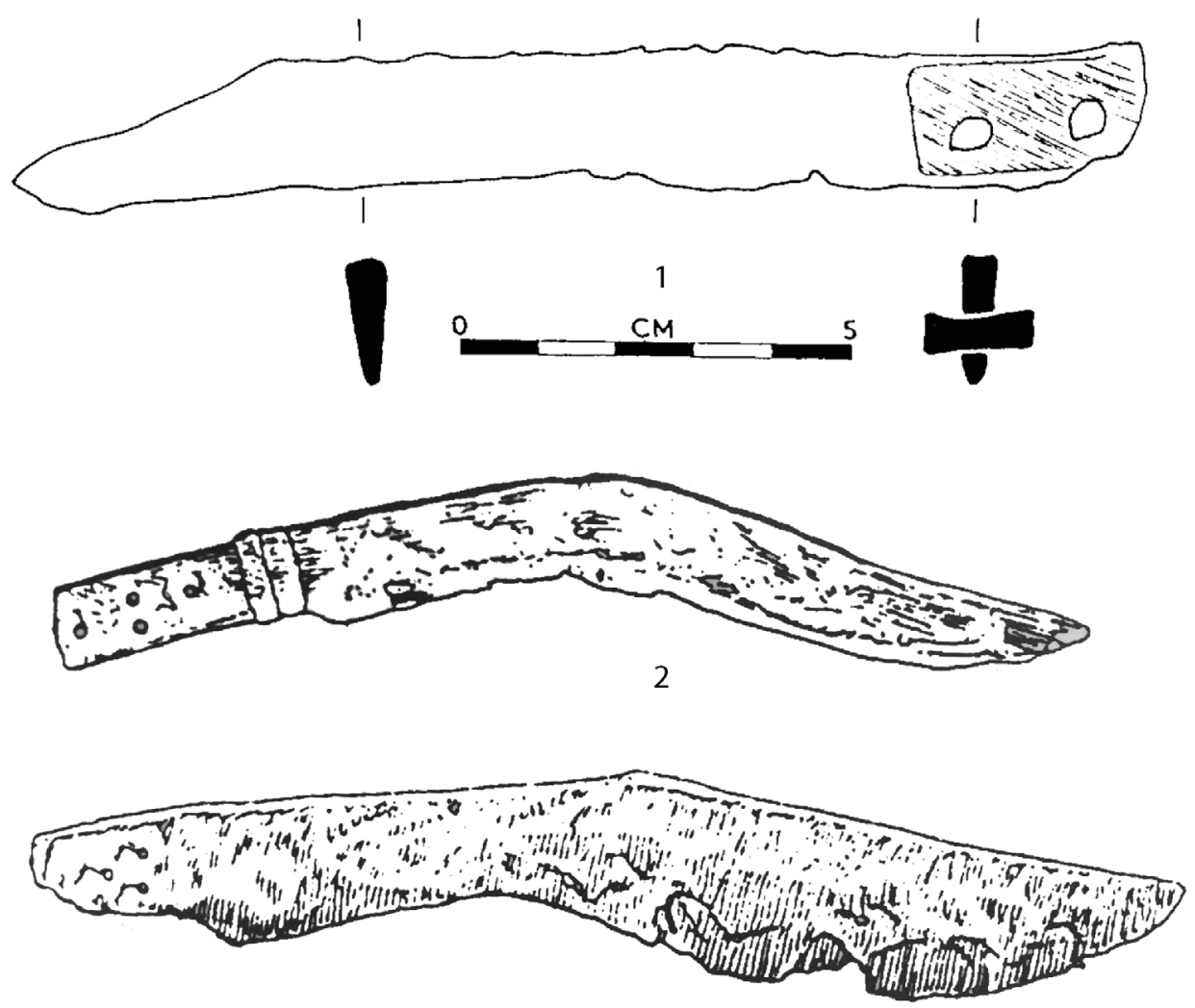

Figura 1. 1) Cuchillo de tipo Grand Bassin I recuperado en la tumba 45 de la necrópolis de Agde (Nickels 1989: fig. 66); 2) Cuchillos afalcatados de Alcácer do Sal (Mancebo 2000: fig. 3, 6, según Schüle).

En el marco de un proyecto iniciado en el año 2000 y que se centra en el estudio del poblamiento protohistórico de la cuenca minera del Baix Priorat (Tarragona) y sus relaciones con el ámbito fenicio (Rafel et al. 2019) presentamos en las líneas que siguen la revisión de los elementos de hierro documentados en la necrópolis del Calvari (El Molar, Tarragona), cuya publicación por Vilaseca (1943) ha sido seguida por los diversos autores que se han referido a ellos sin revisar los objetos en sí mismos y basándose solo en las láminas publicadas por dicho autor. Para el presente trabajo se han examinado los cuchillos de hierro de la necrópolis depositados en el Museu Salvador Vilaseca de Reus, se han restaurado de nuevo dos de ellos por parte de Carmen Prats, responsable del Laboratori d'Arqueologia de la Universitat de Lleida, y se ha realizado una nueva documentación gráfica del conjunto. Asimismo, Raquel Piqué ha examinado los restos de madera conservados en los dos ejemplares restaurados de nuevo.

Los ítems férreos de que tratamos en el presente artículo se inscriben en la I Edad del
Hierro. Sin embargo, conviene señalar que los primeros objetos de este metal en la Península Ibérica se documentan en el Bronce Final, en un horizonte claramente precolonial en cuyo marco su interpretación es discutida (Almagro-Gorbea 1993; Ruiz-Gálvez 1998: 296-304, 319-20; Pereira Sieso et al. 2003; Vilaça 2006; Álvarez-Sanchís et al. 2016; Pare 2017). Se trata de piezas importadas cuyo origen debe buscarse en el ámbito mediterráneo y que habrían llegado a territorio peninsular como resultado de los contactos que preceden a las primeras colonias fenicias (Almagro-Gorbea 1993; Ruiz-Gálvez 2005: 32528). Algunas de estas primeras evidencias se asocian a dataciones radiocarbónicas que nos permiten transitar terreno seguro (Vilaça 2006). No es así, por desgracia, en relación a las de la I Edad del Hierro, afectadas por el tramo amesetado de la curva de calibración en esta etapa. Este conocido problema introduce aún más dificultades en la interpretación de los objetos de hierro de este horizonte y, más en concreto, en su adscripción cronológica precisa, que solo puede ser fijada por el 
momento a través de la metodología tipológico-estratigráfica.

\section{El conjunto arqueológico del Calvari del Molar y su cronología}

El conjunto arqueológico del Calvari del Molar, compuesto por un poblado y una necrópolis, se encuentra en el término municipal de El Molar (Priorat, Tarragona). El poblado se sitúa en la parte más alta de un cerro con excelente visibilidad sobre las tierras circundantes, emplazándose la necrópolis a unos $100 \mathrm{~m}$ de distancia en dirección suroeste y a una cota unos $15 \mathrm{~m}$ inferior. El conjunto es bien conocido en la bibliografía arqueológica desde las excavaciones efectuadas por Salvador Vilaseca en 1930 y publicadas más de diez años después. Sus trabajos en la necrópolis permitieron identificar 171 enterramientos que fueron íntegramente excavados, mientras que en el poblado únicamente efectuó un corte en el que salieron a la luz varios ámbitos (Vilaseca 1943). Estas primeras excavaciones fueron objeto de revisión posterior en diversos trabajos, destacando por su mayor profundidad los de Gonzalo Ruiz Zapatero (1985) y especialmente Pedro V. Castro (1994). Entre 2001 y 2012 llevamos a cabo una nueva etapa de excavaciones en el poblado, que permitió identificar los principales rasgos de su trama urbana y establecer su cronología entre los siglos VIII y primer cuarto del VI ane. Al mismo tiempo, las investigaciones realizadas en la comarca -incluyendo excavaciones, prospecciones y estudios analíticos- mostraron el relevante papel desempeñado por el asentamiento en la explotación de los recursos minero-metalúrgicos, principalmente de plomo, del Baix Priorat (Rafel et al. 2019). Más adelante volveremos sobre esta cuestión.

La necrópolis fue fechada inicialmente por su excavador en los siglos VIII-VI ane (Vilaseca 1943: 58). Posteriormente, en su secuen- ciación de los Campos de Urnas (CCUU) tarraconenses este mismo autor la incluyó como yacimiento tipo de su fase III (siglos VII-VI ane) (Vilaseca 1954: 78). Con motivo de su intervención en la necrópolis de Can Canyís volvió sobre su periodización de los CCUU tarraconenses modificando de nuevo su cronología y situando su fase III entre 750 y 600 ane (Vilaseca et al. 1963: 88). Ya en la década de 1970 Martín Almagro-Gorbea (1977) propuso una nueva periodización de los CCUU catalanes y situó el inicio de la necrópolis del Calvari en su período IV, que fechó entre 800 y 700 ane. En esta misma línea, a mediados de los 80 Ruiz Zapatero propuso la siguiente periodización para nuestra necrópolis: Molar Ia (inicios del siglo VIII ane), Molar Ib (siglo VIII y primera mitad del VII ane) y Molar II (700-600 ane) (Ruiz Zapatero 1985: 162-70). En los años 90 el yacimiento fue objeto de un nuevo estudio de conjunto que cuestiona las bases sobre las que se habían construido las secuencias cronológicas anteriores y propone un margen cronológico para la necrópolis de $\mathrm{El}$ Molar entre $c .800$ y c. 600, sugiriendo que algunos enterramientos podrían ser anteriores al siglo VIII cal ANE (Castro 1994: 130-32, 135 $48,154)$, una propuesta que, con bases diferentes, no difiere mucho de la de Almagro-Gorbea. Trabajos más recientes de Ruiz Zapatero distinguen únicamente dos fases, la I situada entre c. 800-700 ane y la II que se extendería a lo largo de la centuria siguiente (c. 700-600 ane) (Ruiz Zapatero 2004). Ya en este siglo se llevan a cabo dos dataciones radiocarbónicas sobre hueso cremado procedente de las tumbas 94 y 155 cuyos resultados, no exentos de problemas, parecen sugerir una datación de la fase Ib de Ruiz Zapatero, a la que pertenece la tumba 94, en la primera mitad del siglo VIII cal ane y, en consecuencia, una fecha anterior para la fase Ia, en la línea de lo propuesto por Castro (Rafel y Armada 2008). 


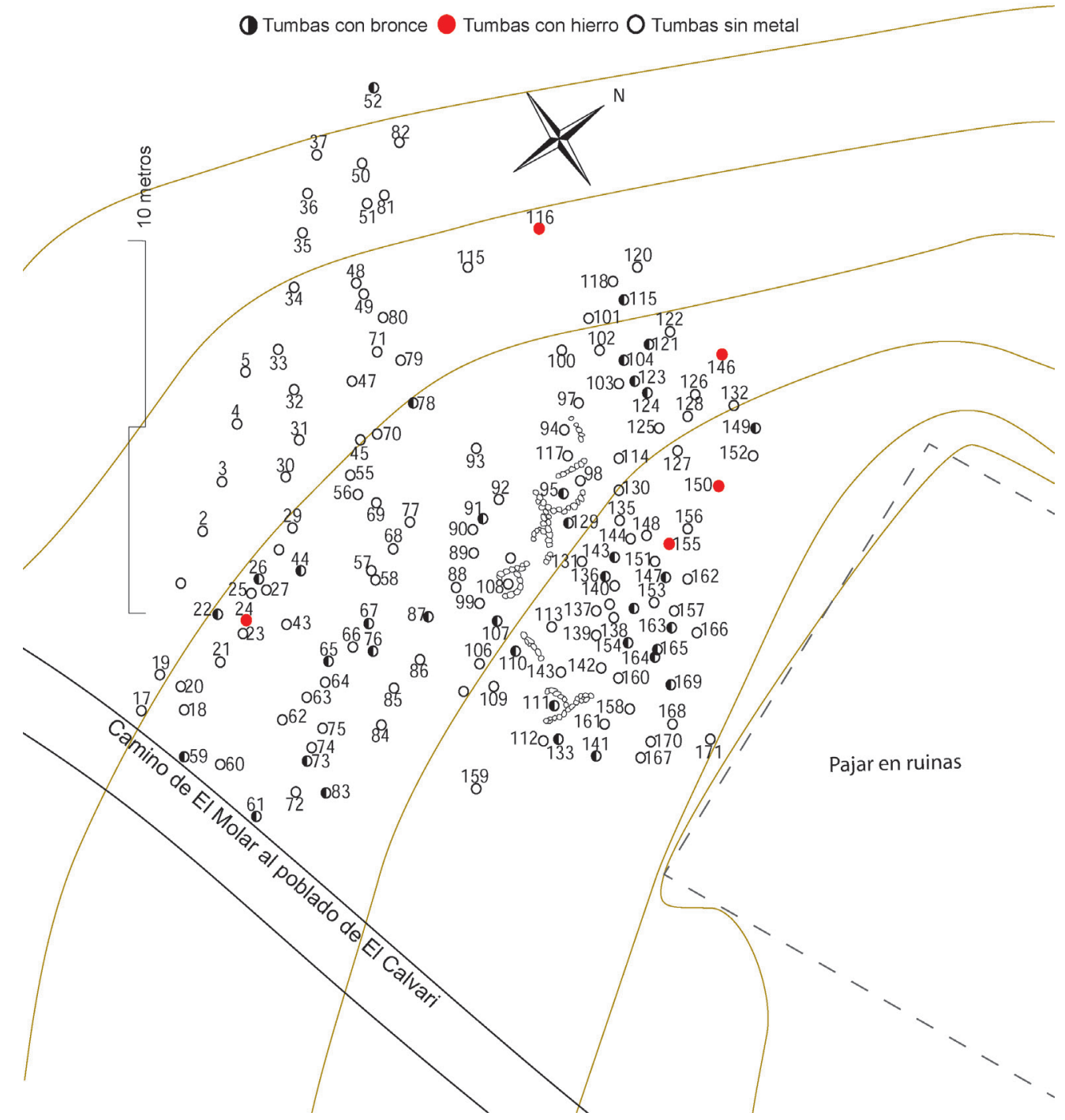

Figura 2. Planta de la necrópolis del Calvari de El Molar redibujada sobre Vilaseca (1943) y situada topográficamente.

\section{Las piezas de hierro recuperadas en la necrópolis del Calvari del Molar}

La necrópolis proporcionó cinco tumbas con hierro: 24, 116, 146, 150 y 155 . Todas ellas están situadas en zonas perimetrales del conjunto (Fig. 2). En la primera se documentó una anilla, en el resto cuchillos. Sin contexto se recuperaron también una lengüeta y un fragmento de hoja de cuchillo. En total, pues, se han documentado siete piezas de hierro, de las cuales seis son instrumentos de corte. A diferencia de otros autores, como veremos, Castro consideró todos los elementos de corte en hierro de la necrópolis como cuchillos tipo Grand Bassin I y tuvo en consideración también uno de los fragmentos recuperados sin contexto. Describió los cuchillos como de dorso recto y filo curvo, con remaches para ajustar el mango, sin más precisiones (Castro 1994: 106). En cuanto a la cronología, los vinculó al intercambio con el mundo fenicio y se apoyó en las dataciones al alza de la presencia fenicia en la Península para afirmar que "la existencia de determinados centros de producción [se refiere a centros de producción fenicios peninsulares] de objetos de hierro desde c. $900 \mathrm{cal}$ ANE asegura que el acceso a cuchillos de este metal por parte de la comunidad del Molar resultaba posible" (Castro 1994: 145), sin decantarse, pues, por cronologías precisas, más allá de esta afirmación de carácter general. Por su parte, Ruiz 
Zapatero (1985) muestra indecisión en la clasificación de estos ítems, como veremos más abajo en detalle.

Presentamos a continuación cada una de estas tumbas y sus objetos de hierro:

- Tumba 24: Se trata de un enterramiento situado en la zona sur de la necrópolis, casi en su extremo. Se documentó en él una anilla de hierro de $25 \mathrm{~mm}$ de diámetro y función desconocida junto a una urna de perfil con carena muy redondeada, de modo que adopta una morfología de tendencia esferoidal, cuello exvasado al que le falta el labio, pie anular bajo y tres pezones sobre la línea del diámetro máximo (Fig. 3). Una torques filiforme de bronce con extremos doblados y dos anillos también de bronce completaban el conjunto (Vilaseca 1943: 27, láms. II y XII). Aunque incompleto, el osario de esta tumba tiene características que lo engloban en la fase II de la necrópolis, como ya observó Ruiz Zapatero (1985: 162-70).

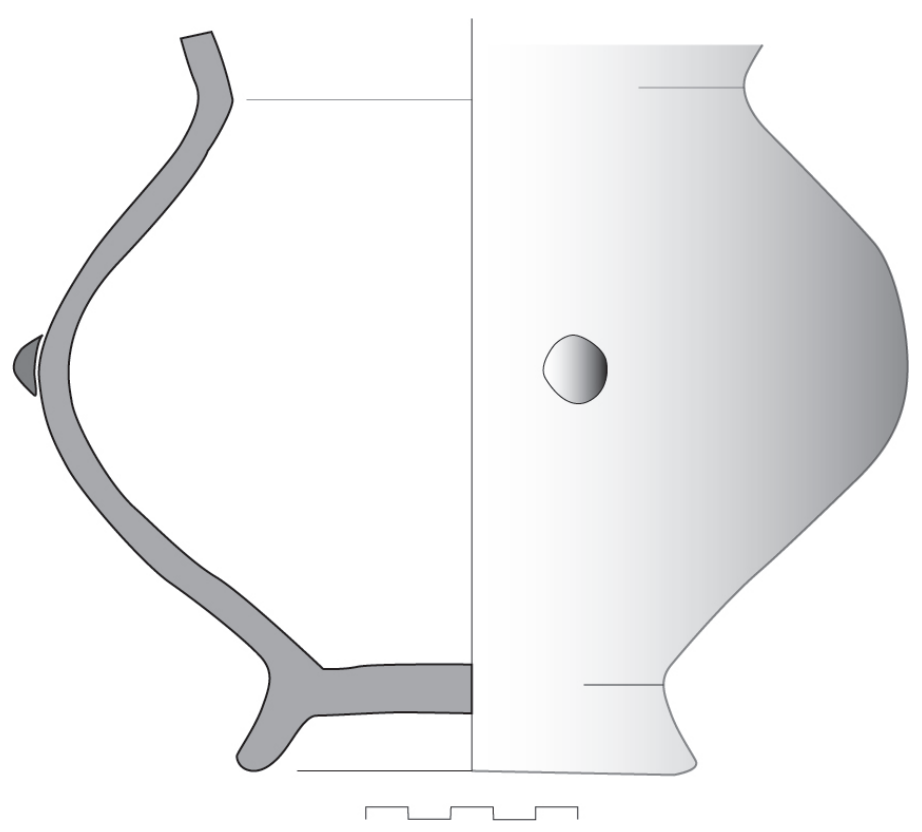

Figura 3. Urna de la tumba 24 del Calvari (Castro 1994: lám. VI, 4, redibujada).

- Tumba 116: Enterramiento situado en el extremo norte-noroeste de la necrópolis. El osario cerámico estaba muy fragmentado, de modo que no fue posible reintegrarlo ni apreciar sus características morfológicas, a excepción del hecho de que tenía pie anular. El único ajuar de acompañamiento lo constituía el cuchillo, que Vilaseca describe como un cuchillo o navaja de hierro con dos remaches de bronce (Vilaseca 1943: 31, lám. XVI, 2). Se trata de un cuchillo completo de 12,5 $\mathrm{cm}$ de longitud (Museu Salvador Vilaseca, NI 5058, 1.16.3.6) que presenta el dorso recto, el extremo distal suavemente descendente en el último quinto de la hoja y la punta ligeramente incur- vada hacia arriba, rasgo este último que lo diferencia de los ejemplares prototípicos de Grand Bassin I. Conserva la lengüeta con dos remaches de hierro -y no de bronce, como afirma Vilaseca- para sujetar el mango (Fig. 4). Fue objeto de una nueva restauración que permitió apreciar que conserva restos de madera mineralizada de las cachas del mango, aunque, una vez examinados, se comprobó que son demasiado delgados para poder identificar la especie (Fig. 4, 3). Corresponde al tipo A1c de Filippini, cuya cronología de inicio se sitúa $c$. 800 ane y perdura hasta el siglo V (Filippini 2007: figs. 3 y 6). 

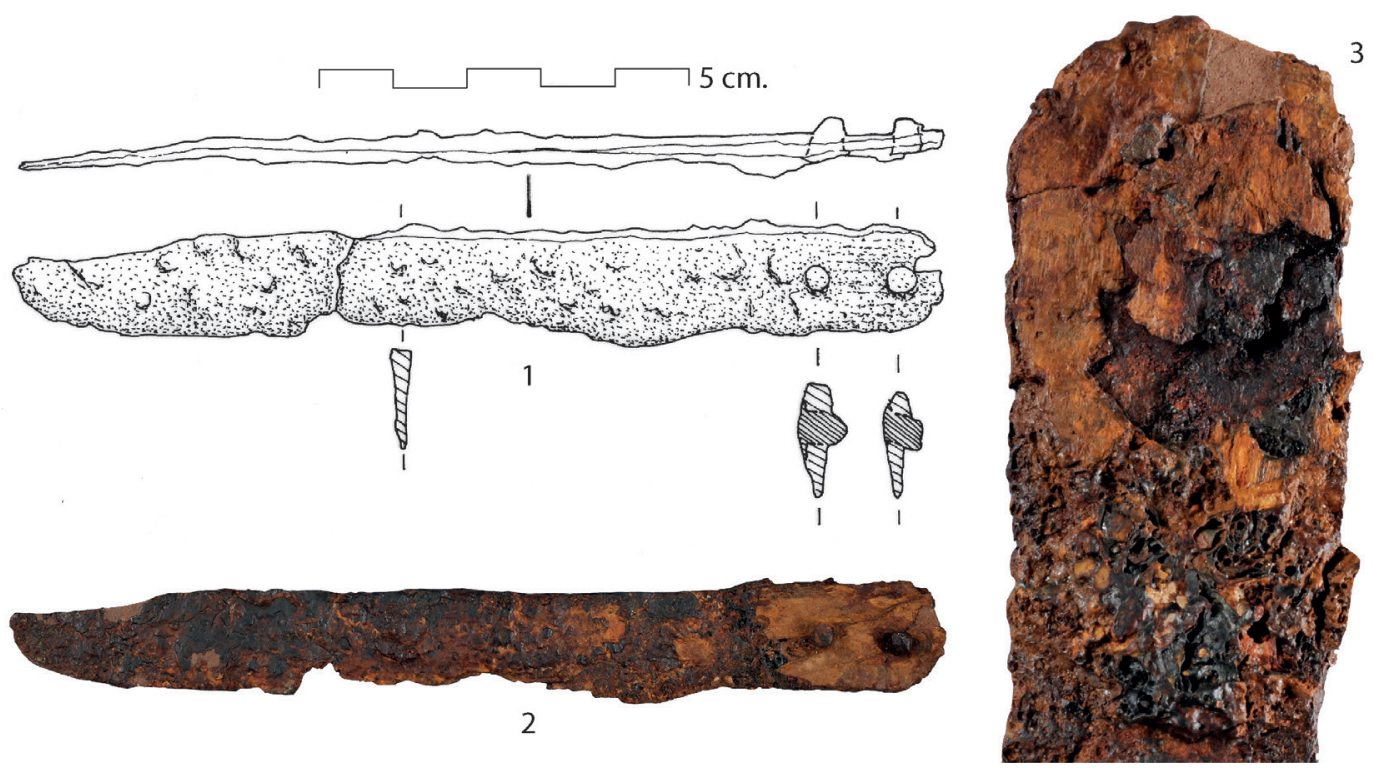

Figura 4. Cuchillo de la tumba 116 del Calvari: 1-2) vista general (dibujo: Raimon Graells y Antoni Llussà; fotografía: Servei de Reprografia de la Universitat de Lleida); 3) detalle de la empuñadura (Servei de Reprografia de la Universitat de Lleida).

Uno de los paralelos más cercanos a esta pieza procede de la tumba 367 de la necrópolis de Moulin (Fig. 5, 1) y ha sido fechado en el último cuarto del siglo VIII ane, aunque tiene paralelos más tardíos en las necrópolis de Las Peyros de Couffoulens y de Saint Julien de Pézenas. Pequeños cuchillos, anillas y agujas constituyen los primeros objetos de hierro de la necrópolis de Moulin (Janin et al. 1998: 376). La tumba 367, asignada a la fase III de la necrópolis (finales del siglo VIII-650 ane), cuenta con un rico ajuar donde se contabilizan 14 vasos cerámicos, restos de un vaso de bronce, una navaja tipo Mailhac II y una aguja de cabeza enrollada de hierro (Janin et al. 1998: 245-49, 377, figs. 361-62). Se trata en este caso de un cuchillo conservado completo de tamaño muy similar al nuestro $\square 13 \mathrm{~cm}$ de longitud $\square$ filo muy ligeramente curvado y dorso recto que desciende en su extremo distal (aproximadamente en el último cuarto de la hoja) y que presenta la punta ligeramente incurvada hacia arriba (Janin et al. 1998: fig. 361; Janin y Chardenon 1998: fig. 1). Conserva buena parte de la lengüeta con dos remaches y un pequeño fragmento de una cacha de hueso. Se considera uno de los primeros objetos de hierro de Rousillon-Languedoc Occidental (Janin y Chardenon 1998). Le diferencia del de la tumba 116 del Calvari el hecho de que el descenso del dorso es más acusado.
Ruiz Zapatero sitúa el enterramiento Molar 116 en el momento final de su Fase II, sin duda por la presencia de este cuchillo, que él describe como de tipo Gran Bassin I (Ruiz Zapatero 1985: 162-70, 851). En la necrópolis del Pla de la Bruguera (Castellar del Vallès, Barcelona), fechada entre 650 y 575 ane, se documentó hierro en ocho de sus estructuras sepulcrales $(6,8,18,21,22,33,34)$, computándose un total de 13 cuchillos que sus excavadores consideran de tipo Grand Bassin I (Clop et al. 1998). De modo general los fechan a mediados del siglo VII ane, basándose en paralelos con Gran Bassin I, Agullana, Pedrós y Molar. Sin duda, las asociaciones de las piezas férreas de esta necrópolis apuntan a cronologías bajas para las mismas. En la estructura 8 se documentó un cuchillo de hierro en un apreciable estado de conservación (Fig. 5, 2) de tipología asimilable al de la tumba 116 del Calvari del Molar y unos $17 \mathrm{~cm}$ de longitud.

La extensa necrópolis de incineración de Can Piteu-Can Roqueta (Sabadell, Barcelona), con más de un millar de tumbas, ha proporcionado un extraordinario conjunto de 123 cuchillos de hierro, 75 de los cuales completos. Su estudio se presentó en un congreso en 2008, del que desgraciadamente solo se han publicado hasta la fecha los resúmenes de las comunicaciones (López Cachero y Rovira Hortalà 2008) por lo que su conocimiento 
debe basarse principalmente en la tesis de Francisco Javier López Cachero (2005), dedicada a la cerámica del yacimiento, en un Trabajo de Final de Grado por él dirigido (Zamora 2014-15) y en el estudio de algunos materiales broncíneos a ellos asociados. Cuchillos y fíbulas son los hallazgos metálicos más recurrentes en el yacimiento. Los primeros cuchillos de hierro se asocian a fíbulas de pivote y de doble resorte y han sido fechados a finales del siglo VIII ane, aunque su presencia se prolonga toda la duración de la necrópolis (siglo VII e inicios del VI ane), pero ya asociada a fíbulas serpentiformes de hierro (López Cachero 2005: 480-82, 517, tabla 33). Al menos uno de los cuchillos de Can Piteu-Can Roqueta (CPR-645-45) $\square$ que Zamora (2014-15: 3334,75 ) incluye en su subgrupo 5 (Fig. 5, 3) $\square$ puede ponerse en relación tipológicamente con el ejemplar de la tumba 116 de El Molar, aunque es de un tamaño mucho menor que el nuestro.
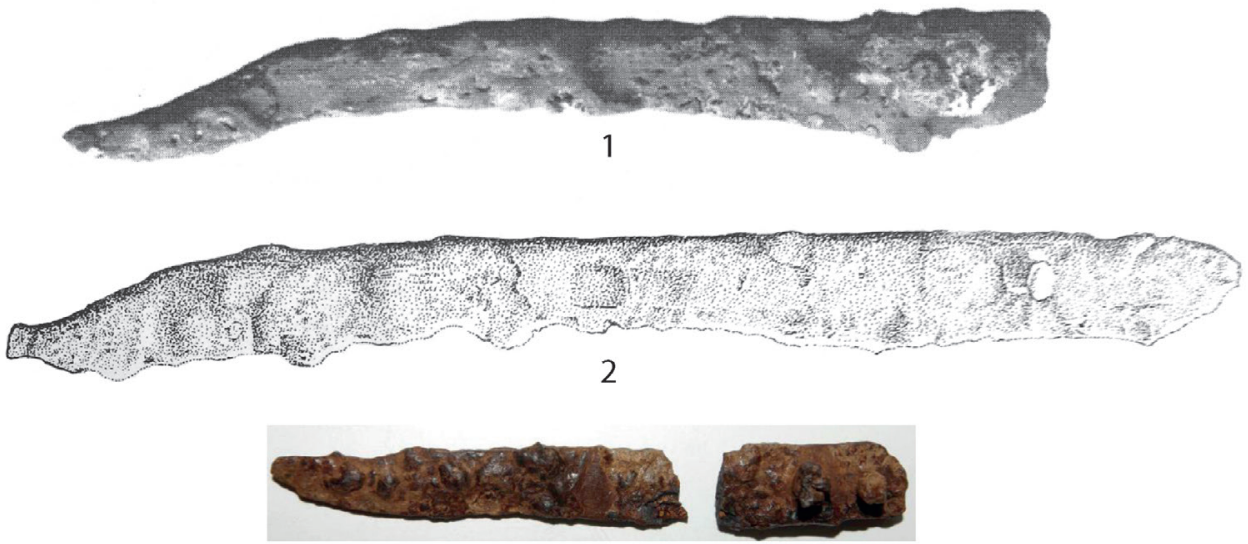

3

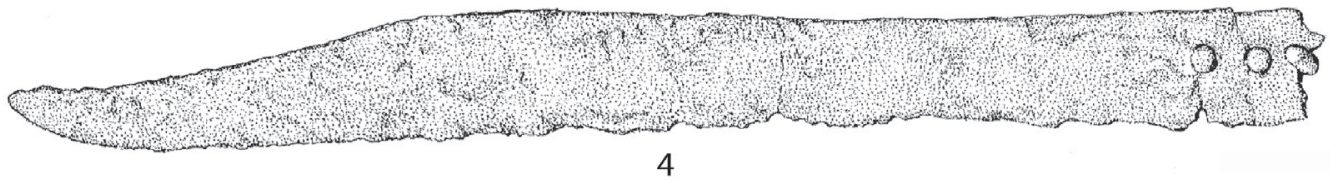

4

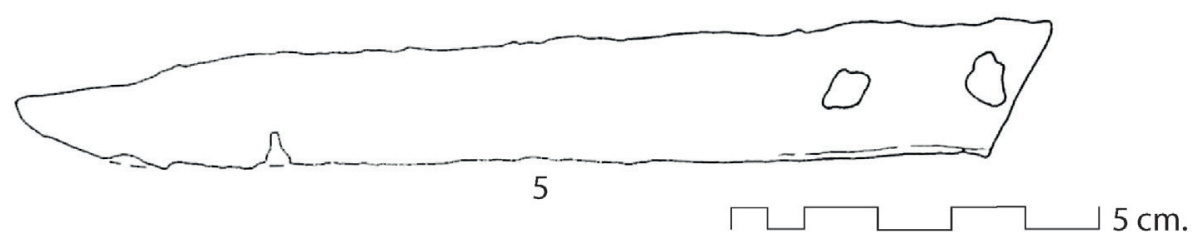

Figura 5. 1) Cuchillo de la tumba 367 de la necrópolis de Moulin (Janin y Chardenon 1998: fig. 2); 2) Cuchillo de la tumba 8 del Pla de la Bruguera (Clop et al. 1998: fig. 12); 3) Cuchillo CPR-645-45 de Can Piteu-Can Roqueta (Zamora 2014-15: 75); 4) Cuchillo de la tumba 361 de Agullana (Toledo y Palol 2006: fig. 136 A); 5) Cuchillo de la tumba 115 de la necrópolis de Agde (Nickels 1989: fig. 149).

En Agullana (Can Bech de Baix, Girona), seis de los cuchillos documentados se asocian a urnas de perfiles angulosos y decoración acanalada que Toledo y Palol (2006: 257) sitúan en la fase IIa de la necrópolis, para la que proponen una datación de la primera mitad del siglo VIII ane. El cuchillo de la tumba 361 constituye un paralelo claro de nuestro ejemplar, que los autores ponen en relación con el de la tumba 367 de Moulin y con el cuchillo de la tumba 1 de la necrópolis de Setefilla (Toledo y Palol 2006: 110-11, 258, fig. 136A; Aubet 1975: fig. 9) (Fig. 5, 4). Se ha paralelizado también con un cuchillo de la necrópolis de la Muralla NE de Empúries (L'Escala, Girona), concretamente el de la tumba 11 (Almagro Basch 1955: 390; Pons 1984: fig. 8, 2), fechable en el siglo VI ane. El cuchillo de Agullana se diferencia del de la tumba 116 del Calvari por el descenso del dorso, situado en el de 
Agullana en el tercio distal y, como en el caso de Moulin, con descenso más acusado, y por la presencia de tres remaches.

En la necrópolis de Agde, fundamental en la caracterización del horizonte Grand Bassin I (Nickels 1989: 445-57), se documentan cuchillos en 33 de sus tumbas. La gran mayoría pertenece al tipo Grand Bassin I, aunque algunos se apartan de los modelos canónicos. Entre ellos cabe citar uno de los dos depositados en la tumba 115 (Fig. 5, 5), que se fecha en el tercer cuarto del siglo VII ane por la presencia en el ajuar de una copa subgeométrica y que se asemeja tipológicamente al del Calvari 116 (Nickels 1989: 175-77, 455, fig. 149; Nickels et al. 1981). También de punta ascendente son los ejemplares de las tumbas 72 y 126 de la misma necrópolis (Nickels 1989: figs. 107 y 167).

- Tumba 146: Situada en el extremo norte de la necrópolis, Vilaseca (1943: 33) refiere que la urna de este enterramiento pudo ser parcialmente reconstruida y que su perfil "reproduce el tipo de la 19" (Fig. 6, 1), si bien no indica si, como ella, tenía decora- ción acanalada. Castro no la localizó en los fondos del Museu Salvador Vilaseca (Reus). Contenía como único ajuar lo que Vilaseca describió como un cuchillo o navaja de hierro con dos remaches de bronce. Se trata de una lengüeta de cuchillo incompleta (long. $54 \mathrm{~mm}$ ) que conserva un remache de hierro (Museu Salvador Vilaseca, NI 4720-17-1) (Fig. 6, 2). La exigüidad de lo conservado no permite más precisiones sobre su tipo. En cuanto al osario, correspondería a una fase inicial de la necrópolis si damos por buena la identificación de Vilaseca con el tipo de la tumba 19, que presenta rasgos arcaicos: cuerpo marcadamente bicónico con carena redondeada, inflexión borde-cuello muy marcada y desarrollo recto de este último. La parte superior del cuerpo presenta acanalados horizontales y en chevron. Ruiz Zapatero (1985: 162-170) incluye la urna 19 en su fase $\mathrm{Ib}$, indicando que correspondería al tramo final de la misma, en la primera mitad del siglo VII ane, aunque por nuestra parte creemos que puede sugerirse una cronología entre finales del siglo VIII ane y mediados del VII.

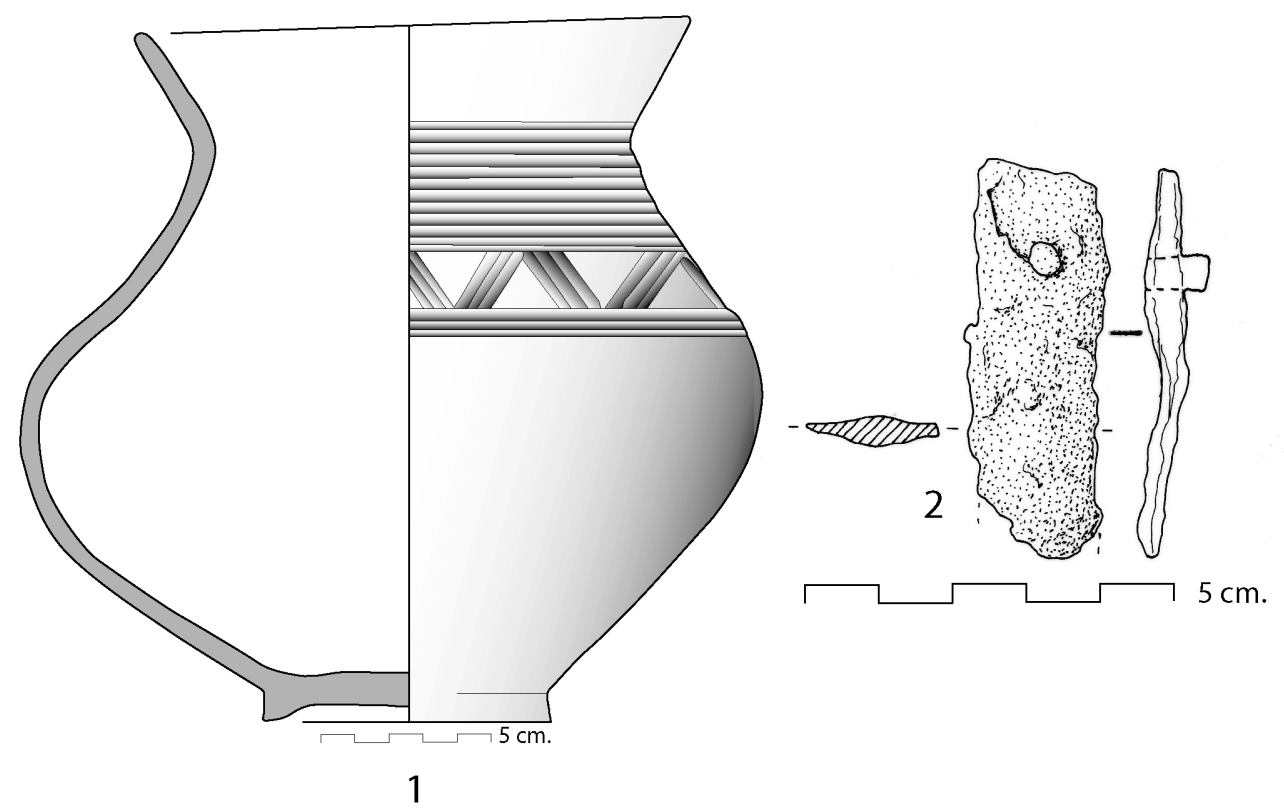

Figura 6. 1) Urna de la tumba 19 del Calvari (Castro 1994: lám. VI, 3, redibujada); 2) Empuñadura de cuchillo de la tumba 146 del Calvari (dibujo: Raimon Graells y Antoni Llussà).

- Tumba 150: Situada en el extremo norte-nordeste de la necrópolis, Vilaseca (1943: 33) describe la urna de este enterramiento como bicónico-esférica con tres pe- zones equidistantes y pie saliente (Fig. 7, 1). Refiere que contenía únicamente una navaja de afeitar de hierro (Vilaseca 1943: lám. XVI, 2). Se trata de la hoja casi com- 
pleta de un cuchillo de dorso muy ligeramente incurvado y filo curvo de $124 \mathrm{~mm}$ de longitud total conservada (Museu Salvador Vilaseca, NI 5861) (Fig. 7, 2 y 3). Aunque no podemos determinar con exactitud el carácter del extremo distal, roto, en la clasificación de Filippini el tipo más próximo a nuestro ejemplar correspondería al Ala, con una cronología de $c$. 740 hasta el siglo $\mathrm{V}$ ane, aunque no podemos excluir una correspondencia con el tipo A3a, fechado entre 675 y 575 ane (Filippini 2007: figs. 3 y 6). Ruiz Zapatero (1985: 851) la considera una navaja de afeitar rectangular, si bien en su clasificación en fases del conjunto de la necrópolis incluye la tumba 150 en el momento final de su fase II, junto con la tumba 116 "por la presencia de cuchillos de hierro de tipo Grand Bassin I" (Ruiz Zapatero 1985: 162-70). Siguiendo a Ruiz Zapatero, Junyent alude tanto a este sepulcro como al siguiente, el 155, como contenedores de "navajas de afeitar rectangulares de tipo Grand Bassin I" (Junyent 1992: 24). Rovira, por su parte, siguiendo a los autores anteriores considera la pieza de hierro de esta tumba como navaja, sin más precisiones (Rovira 1998: 47). No hay en el contexto catalán paralelos claros para este tipo de cuchillo del Molar; sin embargo, la necrópolis de Can Piteu-Can Roqueta proporcionó dos ejemplares de cuchillo de hierro (CPR-750-A-28 y CPR-5-B-16) que quizás pudieran ponerse en relación con el que nos ocupa, con la diferencia de que son de menor tamaño, el dorso es completamente rectilíneo y la inflexión de la curva del filo es menor (Zamora 2014-15: 70, 80). El osario de esta tumba presenta rasgos que, sin duda, indican una cronología ya en la fase II de Ruiz Zapatero de la necrópolis, momento en que él la sitúa (Ruiz Zapatero 1985: 16270), indicando que correspondería al momento final de dicha fase.
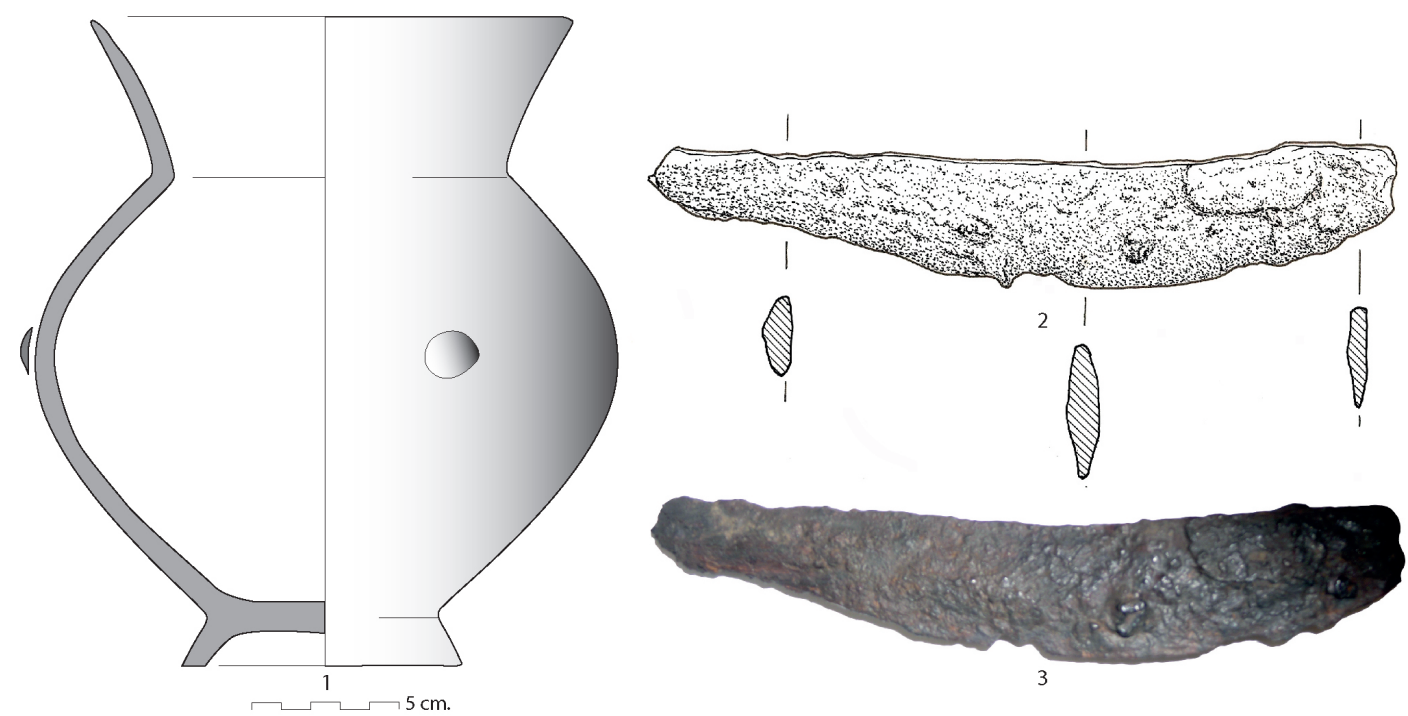

Figura 7. Tumba 150 de la necrópolis del Calvari: 1) Urna (Castro 1994: lám. VI, 21, redibujada); 2-3) cuchillo (dibujo: Núria Rafel y Antoni Llussà; fotografía: Núria Rafel).

- Tumba 155: El enterramiento, muy próximo al anterior, contenía una urna bicónica con carena suave, cuello divergente y pie anular bajo (Fig. 8,1). El cono superior está completamente decorado con surcos acanalados paralelos. Vilaseca refiere que contenía huesos abundantes y "una navaja de hierro de $112 \mathrm{~mm}$ de longitud por $11 \mathrm{~mm}$ de ancho" (Vilaseca 1943: 34, lám. XVI, 2). Ruiz Zapatero (1985: 851) sigue a Vilaseca cuando afirma que la pieza de hierro de esta tumba es una navaja de afeitar, que él añade que es rectangular, pero, como en el caso anterior, en la clasificación en fases de la necrópolis afirma que la urna 155 contiene un cuchillo de hierro (Ruiz Zapatero 1985: 162-70). También como en el caso anterior Rovira considera que la pieza de hierro de esta tumba es una navaja, aunque por error la atribuye a la tumba 156 (Rovira 1998: 
47). Se trata de una hoja de cuchillo que en su estado actual mide $101 \mathrm{~mm}$ de longitud, con dorso ligeramente incurvado que presenta una inflexión ascendente en su cuarto distal, al que le falta el extremo, y un filo manifiestamente curvo. Al igual que el ejemplar de la tumba 150 , podría corresponder a los tipos A1a ó A3a de Filippini. Aunque Ruiz Zapatero tiende a rebajar las cronologías en función de la presencia de hierro, en este caso la evidente antigüedad de la urna del enterramiento le lleva a colocarla en el momento final de su fase Ib, indicando que debe fecharse en la primera mitad del siglo VII ane (Ruiz Zapatero 1985: 852); en otro lugar, en cambio, atribuye las cuatro tumbas con hierro de la necrópolis a su fase II (Ruiz Zapatero 1985: 851 ), indicando todo ello las dudas que le genera la asociación de hierro a un osario antiguo. Por nuestra parte, con toda la prudencia que los elementos de datación con que contamos aconseja, nos inclinamos por situar el osario cerámico de esta tumba a finales del siglo VIII ane o, como muy tarde, en los inicios del VII. Se trata de un perfil con un paralelo claro en la unidad de enterramiento T27 de la necrópolis del Coll del Moro (Gandesa, Tarragona), fechado a finales del siglo VIII ane, que presenta un perfil muy semejante, con pie anular bajo, igual que el vaso que nos ocupa, y en el que a la decoración de acanalados paralelos en la parte superior se suman círculos rehundidos y tetones (Rafel 1991: 65-67). También próxima a la urna Molar 155 se encuentra la H412 de la necrópolis de Roques de Sant Formatge (Seròs, Lleida), que se correspondería con un horizonte Vilaseca II, con la diferencia de que presenta lo que parece un pie indicado y una unión borde-cuello más marcada, rasgos ambos que sugieren una mayor antigüedad que nuestro ejemplar (Pita y Díez-Coronel 1968: 47-48, lám. $\mathrm{X})$. Castro incluyó la urna de este sepulcro en su Forma I, manifestando que creía que formaba parte del grupo más antiguo de la necrópolis, a pesar de su asociación a un objeto de hierro (Castro 1994: 37-41, 130). Cabe reseñar, finalmente, que una muestra de hueso cremado procedente de esta tumba fue datada por radiocarbono (Beta202389: $2950 \pm$ 40) proporcionando una fecha calibrada a dos sigmas y con el $95,4 \%$ de probabilidad entre 1273 y 1016 cal ANE. Sin embargo, introduce dudas el hecho de que la muestra doble que se analizó de esta misma tumba proporcionara una datación muy distinta (GrA-23436: $2375 \pm 40$ ), entre 740 y 384 cal ANE $(95,4 \%$ a dos sigmas) (Tabla 1) (Rafel y Armada 2008).

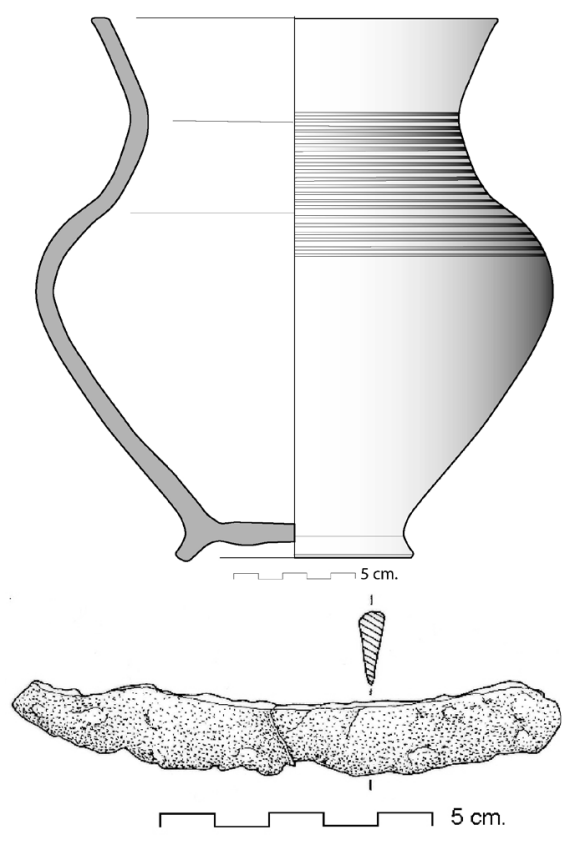

Figura 8. Tumba 155 de la necrópolis del Calvari: 1) Urna (Castro 1994: lám. VI, 22, redibujada); 2) Cuchillo (dibujo: Raimon Graells y Antoni Llussà). 


\begin{tabular}{|l|l|l|}
\hline Código laboratorio & Edad radiocarbónica & Calibración $(\mathbf{2} \sigma)$ \\
\hline Beta-202389 & $2950 \pm 40$ & $1273-1016(95,4 \%)$ \\
\hline \multirow{3}{*}{ GrA-23436 } & & $740-693(6,3 \%)$ \\
& $2375 \pm 40$ & $\begin{array}{l}665-647(2,9 \%) \\
549-384(86,3 \%)\end{array}$ \\
\hline
\end{tabular}

Tabla 1. Edad radiocarbónica y calibración a dos sigmas de las muestras de la tumba 155 del Calvari.

Programa OxCal v. 4.4.4 (Bronk Ramsey 2009); curva IntCal20 (Reimer et al. 2020).

- Ítems de hierro sin contexto: Se trata de dos fragmentos. El primero de ellos $(\mathrm{Mu}-$ seu Salvador Vilaseca, NI 14145) corresponde a la lengüeta, prácticamente completa, y el inicio de la hoja de un cuchillo recto que presenta dos remaches de bronce y restos de las cachas de madera. El fragmento conservado mide $67 \mathrm{~mm}, 26$ de los cuales corresponden a la lengüeta (Figs. 9, 1-2). El inicio de la hoja parece apuntar a un cuchillo recto. Al igual que el cuchillo de la tumba 116 , esta pieza fue objeto de una nueva restauración y conserva restos de madera mineralizada de las cachas del mango; sin embargo, su examen mostró también en este caso que los restos de madera conservados son demasiado delgados para poder identificar la especie. Igualmente sin contexto se conserva un fragmento de hoja de cuchillo de $51 \mathrm{~mm}$ de longitud (Fig. 9, 3), con filo curvo que parece presentar una inflexión. De ser así, podría corresponder a la parte distal de un cuchillo de un tipo parecido a la pieza de la tumba 155 .
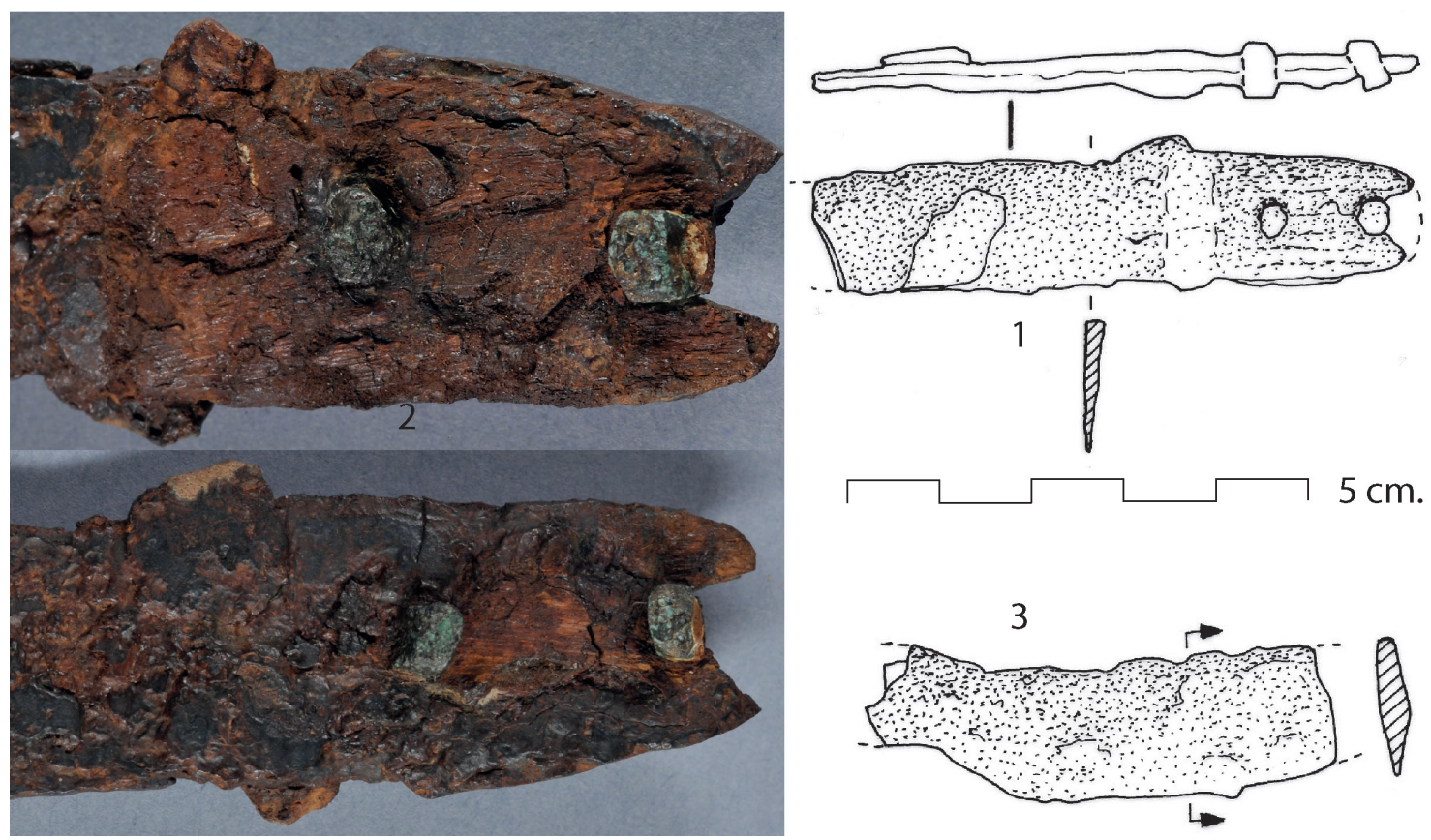

Figura 9. Cuchillos sin contexto de la necrópolis del Calvari: 1) Fragmento de cuchillo que conserva buena parte de la empuñadura y el inicio de la hoja (dibujo: Raimon Graells y Antoni Llussà); 2) Detalle de la empuñadura de la pieza anterior (Servei de Reprografia de la Universitat de Lleida); 3) Fragmento de la hoja del otro cuchillo sin contexto (dibujo: Raimon Graells y Antoni Llussà). 


\section{4. ¿Navajas de afeitar o cuchillos? De tipos, funciones y género}

Como ya hemos indicado, Vilaseca describió las piezas de las tumbas 116 y 146 como cuchillos o navajas, y las de las tumbas 150 y 155 como navajas. La identificación como navajas de los ejemplares de las dos últimas tumbas ha sido seguida acríticamente por la mayoría de autores que han aludido a ellos ${ }^{4}$ e incluso en algún caso se ha definido el tipo de pieza como navaja rectangular (Ruiz Zapatero 1985: 851) o navajas rectangulares tipo Grand Bassin I (Junyent 1992: 24). Creemos que Vilaseca diferencia claramente las piezas de las tumbas 150 y 155 por su filo curvo, distinto de los filos rectos característicos de la mayoría de los primeros cuchillos de hierro del nordeste. En cualquier caso, se trata de piezas que nada tienen que ver con las navajas tipo Mailhac I y Mailhac II de Jockenhövel (1980: 126, Taf. 23) que aparecen en las tres fases de Moulin, es decir, desde el Bronce Final IIIB hasta la I Edad del Hierro, ya en el horizonte Grand Bassin I (Janin et al. 1998: 313-14). Estas últimas son piezas de bronce que se caracterizan por tener un filo doble y una forma tendente a cuadrangular. Los filos, situados en los lados largos, suelen presentar una curvatura más o menos pronunciada. Con muchas variantes, presentan en el centro y entre ambos filos un calado que puede adoptar distintas formas y se sostienen por un mango constituido por una varilla terminada en uno o varios anillos (Fig. 10, 1-2).

Las navajas son poco frecuentes en el nordeste, aunque no ausentes (Agullana, Pi de la Lliura, Can Piteu-Can Roqueta). Se trata en general de navajas de bronce rectangulares, de filo doble, que no tienen parangón en los yacimientos sudfranceses y cuyos únicos paralelos parecen encontrarse, aun siendo escasos, en las Islas Británicas (Jockenhövel 1980: Taf. 1 y 3). Las 23 navajas exhumadas en la necrópolis de Agullana presentan importantes diferencias con respecto a las francesas (Toledo y Palol 2006: 186-90). Las navajas rectangulares de Agullana son piezas de bronce con dos filos cortantes que pueden presentar un mango de lengüeta con remaches o de espiga (Fig. 10, 3-4) o bien no tener mango metálico sino solo dos remaches en la base para fijarlo. Ninguna de estas navajas rectangulares tiene paralelos en Moulin, donde se documentan navajas de los tipos Endingen, Pépieux, Mailhac I y II, Fréjeville y Moux (Janin et al. 1998: 298-300), junto a navajas que Jockenhövel (1980) define como de doble filo con hoja larga ovalada y espiga. Por otra parte, los ejemplares calados, también bien representados en Agullana, presentan, según Toledo y Palol (2006: 190), diferencias sustanciales con el tipo Mailhac, aunque esta última afirmación debe considerarse con prudencia debido a la gran variabilidad de las navajas Mailhac I y II y sus tipos afines. También rectangulares, de doble filo y con dos perforaciones en la base destinadas a sostener el mango son las tres navajas de bronce de las tumbas 26, 77b y 58 de la necrópolis del Pi de la Lliura (Vidreres, Girona), datada entre 950 y 750 ane (Subirà et al. 2012). A falta de datos sobre paralelos tipológicos, más allá de los casos de Can Piteu-Can Roqueta y Agullana, se ha sugerido para estas una posible manufactura local (Pons y Solès 2008: 77), afirmación que, a nuestro entender, se basa en el hecho de que este tipo de navajas del nordeste no presentan paralelos claros fuera de la zona. En cualquier caso, consideramos que nada permite identificar tipológicamente las piezas del Calvari del Molar $\square$ de hierro y con un solo filo $\square$ como navajas.

Otra cuestión distinta de la tipológica es la funcional. Algunos autores, siguiendo las sugerencias realizadas a partir de los ajuares de las necrópolis de Las Peyros de Couffoulens y, especialmente, de Agde (Solier et al. 1976; Nickels 1989), han considerado la posibilidad de que algunos de los cuchillos de hierro presentes en las sepulturas pudieran haber tenido función de navajas de afeitar, especialmente en los casos en que los ajuares contienen dos cuchillos, uno de mayor tamaño y otro pequeño, una asociación que sustituiría a la tan frecuente de navaja y cuchillo. De las 33 tumbas con cuchillos de hierro de Agde, 15 contenían uno y las 18 restantes dos. En las que contenían dos cuchillos, uno de ellos pertenecía al grupo de cuchillos grandes (130 a $168 \mathrm{~mm}$ ) y el otro al grupo de los pequeños (93 a $120 \mathrm{~mm}$ ). Este hecho y la observación de que este tipo de ajuares con parejas de cuchillos parecen sustituir a la asociación navaja-cuchillo característica de Moulin llevan a Nickels (1989: 336-37) a proponer para los mayores una función de 
cuchillo y para los menores un uso como navaja. Aunque se trata de una hipótesis plausi- ble, hasta la fecha nada la apoya fehacientemente (Filippini 2007: 401).
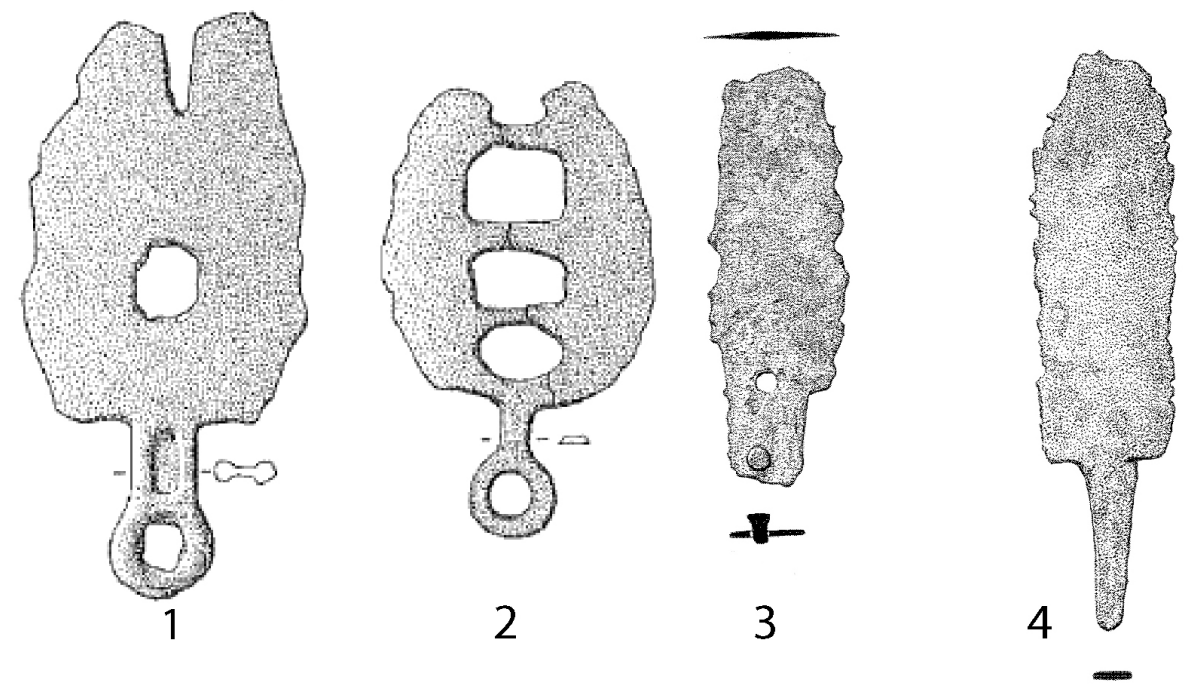

Figura 10. 1-2) Navajas de afeitar de bronce tipo Mailhac I (1) y II (2) (Jockenhövel 1971: Taf. 23); 3-4) Navajas de afeitar de bronce de Can Bech de Baix, Agullana (Toledo y Palol 2006: fig. 200).

Por otra parte, cabe señalar que la función de los cuchillos de hierro ha sido objeto de múltiples propuestas, no excluyentes entre ellas, que Graells (2010: 124) sintetizó: armamento, elemento litúrgico, distintivo social, instrumento cotidiano. Por su parte Almagro-Gorbea y Lorrio (2011: 49-53) desarrollaron largamente, a partir del jienense bronce ibérico del guerrero sacrificando un carnero (MAN NI 1970/14), el valor del cuchillo en los ritos sacrificiales. A menudo la función de estas piezas se ha asociado a su identificación como elementos de ajuares masculinos. Sin embargo, hay que tener en consideración que las atribuciones de sexo basadas en la composición de los ajuares hace ya largo tiempo que se consideran problemáticas, tal como han puesto de relieve diversos autores tanto en el caso peninsular como en otros ámbitos europeos. En la Península Ibérica cabe citar los datos, en algunos casos completamente contradictorios, de las necrópolis ibéricas de El Cigarralejo y Cabezo Lucero (Rafel 2007), así como la presencia de una panoplia completa de guerrero en la tumba femenina de la Dama de Baza (Reverte 1986; Olmos 1986; Blech 1986). Resulta también interesante la presencia en la tumba orientalizante de la Casa del Carpio de dos cuchillos (o un puñal y un cuchillo) acompañando a un enterramiento de una mujer con un neonato fechable en el siglo VII ane (Pereira 2008), en un horizonte cronológico más próximo al del Calvari. En la necrópolis de Medellín los cuchillos de hierro aparecen tanto en tumbas masculinas como femeninas e infantiles (Lorrio 2008: 566). En la necrópolis del Pi de la Lliura el estudio antropológico de los restos humanos proyecta dudas sobre identificaciones tan generalmente admitidas como las de aguja-tumba femenina, navaja-tumba masculina (Subirà et al. 2008: 14849). En el contexto europeo citaremos, a título de ejemplo, los nuevos estudios realizados sobre las necrópolis de Singen y Oudenberg, que contradicen la asociación, clásica en la bibliografía, daga-tumba masculina (Weglian 2001); el estudio de Arnold (1993) sobre el registro funerario de la I Edad del Hierro céltica, que muestra que, si bien las armas se asocian en su mayoría a tumbas masculinas, también se documentan en tumbas femeninas; o la consideración, en relación a los cuchillos de la necrópolis de Las Peyros, de que su aparición en tumbas masculinas no tiene un carácter exclusivo (Solier et al. 1976: 74), mientras que en la de Negabous se propugna una presencia de los cuchillos tanto en tumbas masculinas como femeninas (Porra-Kouteni et al. 2010: 87). Por todo ello, en ausencia de otros datos $\square$ especialmente de carácter antropológico $\square$, consideramos que no se debe aceptar acríticamente la 
identificación con carácter general del binomio cuchillo-tumba masculina.

\section{Sobre cronologías}

Entre los cuchillos de hierro de las deposiciones funerarias del Túmulo A de Setefilla que se recuperaron en buen estado de conservación, destacan por sus similitudes con el tipo que generalmente se asimila a Grand Bassin I los de las urnas 1 y, sobre todo, 62 (Fig. 11, 1 y 2). El primero tiene cuatro remaches de bronce y el segundo tres remaches, también de bronce. El número de remaches es el rasgo que más los aleja del tipo Grand Bassin I, que suele tener dos, excepto en algún caso en que se documentan uno (Grand Bassin) y tres remaches (Can Piteu). Como paralelos para ellos, M. Eugenia Aubet propuso la tumba 9 de la Joya (Fig. 11, 4) y los cuchillos de los Campos de Urnas catalanes y franceses, así como un marco cronológico general para la necrópolis en los siglos VII-VI ane (Aubet 1975: 74-76, 125-27, 15153). La evolución de las cronologías motivó que la propia Aubet y otros autores revisaran al alza estas fechas; sin embargo, ha sido recientemente cuando un programa sistemático de dataciones radiocarbónicas sobre hueso cremado ha confirmado las cronologías altas para las primeras sepulturas del conjunto sepulcral de Setefilla (Brandherm y Krueger 2017). Entre las tumbas fechadas por radiocarbono destaca por la presencia de un cuchillo de hierro la Urna 13, que se sitúa en la primera mitad del siglo VIII cal ane. El cuchillo de este enterramiento es de pequeño tamaño, dorso curvo, punta descendente y lengüeta con tres remaches de bronce (Fig. 11,3) y ha sido puesto en relación con un cuchillo de Laquish fechado c. 1000 ane (Grevey y Gailledrat 2020). Un cuchillo semejante, aunque de mayor tamaño $(14,3 \mathrm{~cm})$ y con cuatro remaches de plata, se recuperó en la Urna 17 de la misma necrópolis, que, aunque datada con la misma técnica, su horquilla calibrada coincide ya con el tramo amesetado de la curva de calibración correspondiente a la I Edad del Hierro. También en el siglo VIII ane podría ubicarse el cuchillo de hierro del túmulo 1 de la necrópolis de Las Cumbres (Puerto de Santa María) (Ruiz Mata y Pérez 1989: 291), aunque, como ya hizo notar Mancebo (2000), los pocos datos publicados no permiten contrastarlo además de que nada sabemos sobre la tipología de dicho cuchillo.
La generalización de los cuchillos de hierro, sin embargo, se produce en el siglo VII ane, como también ha señalado Mancebo (2000).

En Cataluña la tendencia dominante ha sido la de fechar los primeros hierros, a menudo cuchillos, a partir del siglo VII ane (Rovira 1998 y 2004). En relación a la cronología de los ítems de hierro en el nordeste, cabe hacer referencia previamente a la problemática de la propia datación de la I Edad del Hierro. Propuestas recientes sitúan su inicio entre 800 y $775 \mathrm{cal}$ ane (Alonso et al. 2000; Junyent 2002) basándose en el tratamiento estadístico de las dataciones radiocarbónicas del yacimiento de La Fortalesa de Els Vilars (Arbeca, Lleida) y al socaire del envejecimiento general de las fechas, tanto en el Mediterráneo como en la Península Ibérica, propiciado por el Carbono 14 calibrado (Plicht et al. 2009; Núñez 2015; Barceló 2008, con la principal bibliografia anterior). La propuesta del equipo de Vilars ha tenido poco seguimiento pues, por un lado, muchos autores continúan utilizando la cronología tradicional, 650-575 ane, y, por otro, se han realizado planteamientos alternativos, inspirados en el modelo francés, que sitúan entre el Bronce Final y la I Edad del Hierro una etapa considerada de transición y fechada entre $775 / 750$ y $725 / 700$ ane, momento este último en el que se situaría el inicio de la Edad del Hierro (López Cachero y Pons 2008; López Cachero et al. 2009; López Cachero y Rovira 2012). Recientemente, datos basados en la datación arqueomagnética de unidades estratigráficas asociadas a la última fase del yacimiento de la I Edad del Hierro de Sant Jaume (Alcanar, Tarragona) sitúan su abandono en torno a 650 o algo antes, lo que envejecería en un siglo aproximadamente la cronología tradicional de la I Edad del Hierro catalana (Gómez Paccard et al. 2019), una hipótesis grosso modo coincidente con la propuesta del equipo de Vilars. Aunque con avances, tratamos con un problema aún lejos de resolverse, pues se enfrenta no solo a las mencionadas limitaciones de la curva de calibración en la I Edad del Hierro, sino también a una falta de estratigrafías adecuadas y estudiadas modernamente en hábitats. De todos modos, cabe resaltar que la cronología tradicional otorga unos márgenes muy estrechos para una I Edad del Hierro en la que se suceden muchos y densos episodios que difícilmente pueden constreñirse a lo que, en provocativa expresión de E. Junyent (2002: 18), serían unos "patéticos 50 años". 


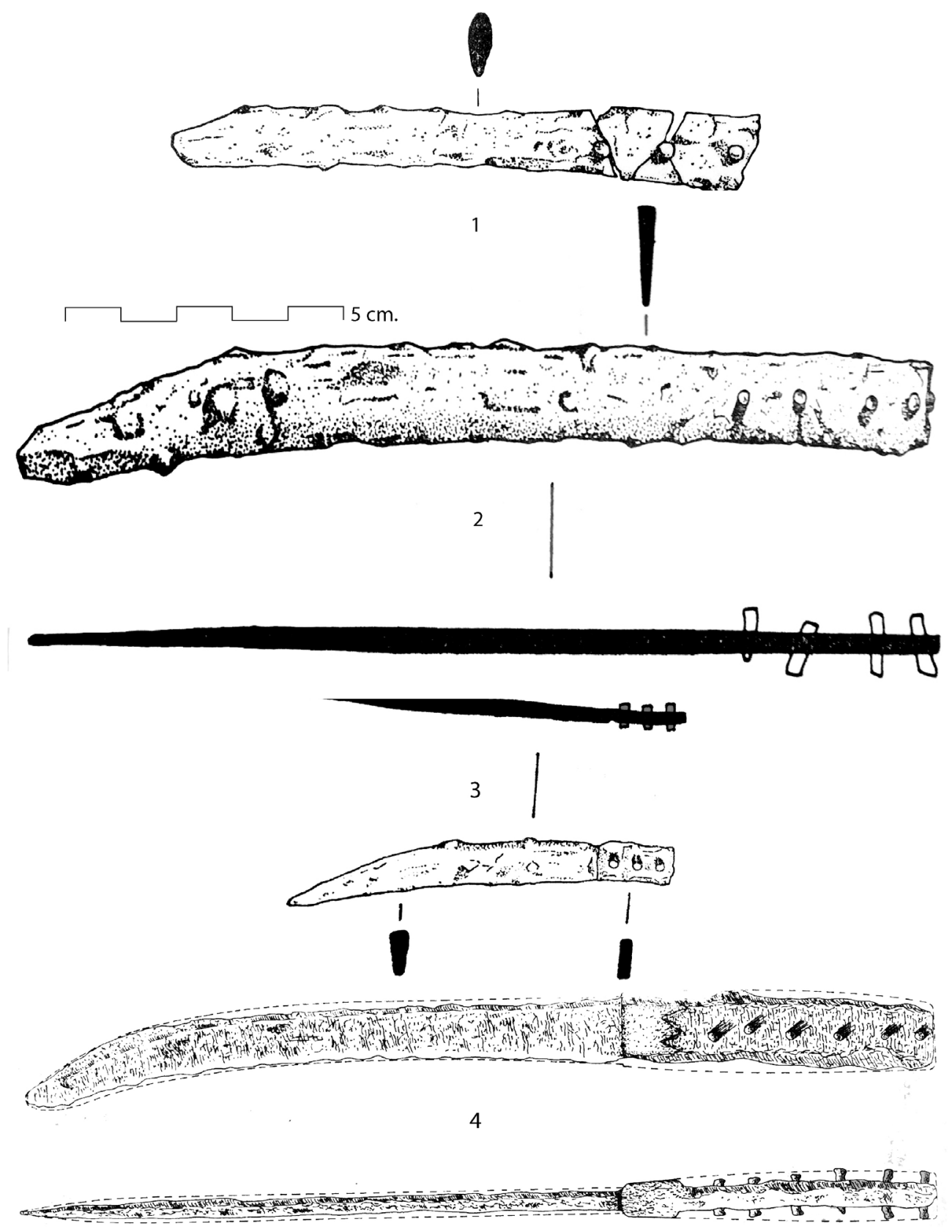

Figura 11. 1-3) Túmulo A de Setefilla, cuchillos de hierro de las urnas 62 (1), 1 (2) y 13 (3) (Aubet 1975: figs. 53; 9, 4 y 19); 4) Cuchillo de hierro de la tumba 9 de La Joya, de $14 \mathrm{~cm}$ de longitud, con tres remaches y una pieza de bronce entre el enmangue y la hoja (Garrido 1970: 45, fig. 31).

Algunos estudios y hallazgos recientes sitúan los primeros cuchillos de hierro del nordeste en el siglo VIII ane. En la necrópolis de Agullana seis de los cuchillos de hierro documentados se asocian a urnas de tipos antiguos que Assumpció Toledo y Pere de Palol (2006: 257) sitúan en la fase IIa de la necrópolis, que fechan entre 800 y 750 ane. Toledo cree que los cuchillos de hierro de Agullana deben fecharse en torno al 750 ane (Toledo
2008: 169, fig. 8). Los contextos de Can Piteu-Can Roqueta situarían los primeros cuchillos de hierro de la necrópolis en el siglo VIII ane (López-Cachero y Rovira-Hortalà 2008; Rovira y López-Cachero 2016) y el cuchillo de hierro, del que desconocemos la tipología, de la tumba 3 de Mas Baleta III (La Jonquera, Girona) se ha fechado en un lapso temporal entre 750 y 650 ane (Tarrús y Carreras 2012: 129). Otros hallazgos recientes, en cambio, 
deben fecharse en el siglo VII ane, como los de la necrópolis del Pla de la Bruguera, donde los diferentes cuchillos se asocian a elementos cerámicos o metálicos de esta cronología, aunque sus excavadores sitúan los cuchillos entre 650 y 575 ane basándose en los paralelos que creen observar con Grand Bassin I, Agullana, Pedrós y El Calvari del Molar (Clop et al. 1998: 121-22). También más tardíos son los cuchillos de la necrópolis de la Muralla NE de Empúries: la tumba 11, por ejemplo, se asocia, entre otros objetos, a un escarabeo de Naucratis de interpretación discutida (Padró 1983: 49; Almagro-Gorbea y Graells 2011: 52), pero en cualquier caso fechable ya en el siglo VI ane. De gran interés son los hallazgos férreos de la necrópolis de Vilanera, en el hinterland emporitano; sin embargo, a la espera de su publicación detallada, no conocemos ni los tipos ni las cronologías exactas de su aparición, si bien la necrópolis de la I Edad del Hierro se ha fechado en la segunda mitad del siglo VII y los inicios del VI ane (Aquilué et al. 2012). Por su excepcionalidad se ha publicado con algo de detalle la tumba EF-9, cuyo ajuar estaba integrado por ocho vasos fenicios, cinco vasos a mano, un simpulum de bronce, un huevo de avestruz decorado, una fíbula de doble resorte y un cuchillo de hierro, cuya tipología se desconoce (Aquilué et al. 2008: 183-84).

Las evidencias directas de trabajo del hierro en la Península Ibérica se localizan en el yacimiento fenicio del Morro de Mezquitilla a finales del siglo IX-inicios del VIII ane y, ya a partir de mediados del VIII y en el VII ane, en los yacimientos también fenicios de El Cortijo, Toscanos, Cerro del Mar y Fonteta. En un contexto indígena, el Castellar de Librilla (Murcia) ha proporcionado evidencias de trabajo del hierro fechables a partir de la segunda mitad del siglo VIII ane, así como Carmona (Sevilla) y Castillejos de Alcorrín (Manilva, Málaga) (Gómez Ramos 1996; Renzi et al. 2013). En el último de ellos se han documentado subproductos de mineral o metal y escoria posiblemente de postreducción, quizás resultado del afino de lupias, todo ello en un horizonte con fechas absolutas entre el último cuarto del siglo IX y finales del VIII (Renzi et al. 2014). En el nordeste se ha documentado un posible horno de reducción de hierro en el yacimiento de La Fortalesa de Els Vilars datado por radiocarbono en torno a 700 ane; sin embargo, se trata de un dato que requiere aún contrastación por la ausencia de elementos asociados, como por ejemplo escorias, que permitan corroborar esta hipótesis (Rovira 2000). Es ya en el siglo VI ane cuando se cuenta con datos firmes de reducción del hierro en la Penya del Moro de Sant Just Desvern (Barcelona) y en Ullastret (Girona) (Rovira 2000). En el yacimiento de la Granja d'Escarp (Lleida), con una datación de primera mitad del siglo VI ane, pero que probablemente tuvo una fase anterior, se ha propugnado la explotación de menas locales de hierro (González et al. 2002), pero no se cuenta con datos directos en contexto de su reducción, por lo que, igual que en el caso de Vilars, es un dato sujeto aún a verificación. Hay que subrayar, no obstante, que se documentan muchas escorias de hierro en el yacimiento, aunque desgraciadamente sin contexto estratigráfico, y hierros manufacturados (cuchillos fragmentados, hacha, escarda) (Vàzquez et al. 2006-07). En cualquier caso, debemos señalar que la ausencia de contextos de trabajo del hierro claros antes del siglo VI ane en Cataluña ha tenido como consecuencia que los ítems de hierro anteriores hayan sido interpretados tradicional, y quizás abusivamente, como resultado del intercambio con comunidades foráneas.

\section{Conclusiones}

A pesar de las evidentes debilidades de las dataciones de la I Edad del Hierro del nordeste peninsular, los datos que presentamos en relación a los ítems férricos de la necrópolis del Calvari del Molar ponen de manifiesto que a menudo han sido datados tardíamente por la simple razón de que hasta fechas recientes también lo ha sido la I Edad del Hierro catalana. Ello ha provocado que se fijara una línea roja en la segunda mitad del siglo VII ane, más allá de la cual no se creía posible situar el hierro. En algunos casos, como el de la tumba 155, arrastrando la evidente tipología antigua de la urna hacia este siglo a causa de la presencia de hierro. Por nuestra parte, proponemos situar tentativamente la primera presencia de hierro en la necrópolis a partir de finales del siglo VIII. No está de más recordar, por otra parte, que, aunque aún sujetos a contrastación, hay algunos datos que permiten proponer fechas al alza para toda la I Edad del Hierro en el nordeste. Eso no significa que todos los enterramientos con cuchillos deban 
situarse en el horizonte cronológico que sugiere la tumba 155, dado que sin duda hay tumbas posteriores.

Hemos visto que los instrumentos de corte documentados en la necrópolis son piezas con dorso y un único filo, lo cual las aleja tipológicamente de lo que se han venido considerando navajas. La autopsia y documentación de las piezas que hemos realizado permitirán juzgar sobre el particular, más allá de las imágenes muy confusas y difíciles de interpretar publicadas hasta ahora.

Aunque los primeros hierros peninsulares son objetos de importación, en Cataluña habría que considerar también la posibilidad, ya apuntada por Ruiz Zapatero (2004: 320), de manufacturas locales anteriores al siglo VI, momento en que, como hemos visto, se fechan con seguridad las primeras actividades siderúrgicas en el nordeste. Desde luego no contamos con datos empíricos que permitan propugnar manufacturas locales anteriores al siglo VI, a excepción del caso, discutido, de Vilars, y por ello debemos mantenernos en una actitud prudente; no obstante, hay que tener presente que las actividades directas de transformación metalúrgica en general son difíciles de detectar arqueológicamente, como lo muestra la poca cantidad de hornos metalúrgicos documentados en relación a la masa de metal circulante. En el caso del bronce las manufacturas locales son detectadas a menudo a través de la presencia de moldes; sin embargo, la inexistencia de la fundición en molde en la siderurgia de estos momentos limita aún más las posibilidades de rastrear las posibles producciones locales.

Sí debemos señalar que en las excavaciones del poblado del Calvari aparecen escasos ítems de hierro, algunos pequeñísimos fragmentos de tipología inidentificable, a excepción de la lengüeta de un cuchillo. Ninguno de estos ítems aparece en los niveles más antiguos del poblado (finales del s. IX/inicios del VIII a mediados del VII ane). Si bien es de rigor señalar que también es muy escaso el bronce, un rasgo que hay que asociar al hecho de que se trata de un poblado abandonado y en el que los materiales exhumados corresponden en su mayor parte a restos de vasos, algunos de ellos muy grandes y/o ya inservibles, y se caracterizan por una notoria ausencia de piezas de metal, a excepción de un pequeño escondrijo documentado en la fase reciente del asentamiento (Montero-Ruiz et al. 2012: 171-74). No hay que olvidar, sin embargo, que en el poblado se han podido documentar directa (molienda de mineral, escorias de plomo, estructura de combustión) e indirectamente (análisis de isótopos de plomo) actividades de extracción de mineral de plomo y cobre de las minas cercanas y transformación de ambos, además de haberse exhumado una estructura de combustión asociada a una tobera de tipo fenicio, sin duda destinada a actividades metalúrgicas que, desgraciadamente, ha sido imposible identificar (Armada et al. 2005; Gener et al. 2007; Rafel et al. 2021). Sin embargo, la posible llegada de hierro a través del intercambio $\square$ especialmente por cuanto se refiere a los ítems más antiguos $\square$ no debe descartarse en absoluto, más si tenemos en consideración que el poblado del Calvari indica claramente que desde el siglo VIII llega al yacimiento cobre de Linares y, más tarde, se documenta su incorporación a los circuitos de abastecimiento vinculados al mundo fenicio, cuyos testimonios más abundantes son la presencia de grandes envases fenicios, por lo que es indudable la inserción de sus habitantes en redes de intercambio a larga distancia (Montero-Ruiz et al. 2012; Rafel et al. 2019).

No vamos a entrar aquí en la cuestión del origen del hierro y de los primeros objetos de este metal, un tema que ha sido largamente tratado y sobre el que, desgraciadamente, no hay datos que permitan añadir nada nuevo a lo ya argumentado por los diversos autores en defensa de su posición, ya sea esta progriega, proetrusca, procontinental o profenicia. Cabe mencionar, no obstante, la reciente propuesta (Grevey y Gailledrat 2020) que incide de nuevo en un origen oriental transmitido por vía fenicia. ${ }^{5}$

La distribución espacial de las tumbas con hierro en el conjunto funerario del Calvari muestra una disposición interesante: las cuatro tumbas con cuchillos se sitúan en el extremo norte del solar funerario en una disposición periférica respecto del resto (Fig. 2), ${ }^{6}$ que podría ser indicativa de modernidad. ${ }^{7}$ La excepción la

El artículo que citamos es un brevísimo resumen, poco ilustrado, de un interesante Trabajo de Máster realizado por Anne-Laure Grevey (Les premiers couteaux en alliage ferreux dans la Péninsule ibérique et le Midi (IXe-premier quart VIe siècle av. n. è.), 2016), desgraciadamente inédito.

Castro (1994: 119) sitúa erróneamente los enterramientos con cuchillos de hierro en el sector sudoeste de la necrópolis.

No hay que obviar, sin embargo, el hecho de que estas tumbas se sitúan en el extremo del solar funerario lindante con una edificación moderna, que no ha sido investigada, por lo que cabe la posibilidad de que la necrópolis continuara (o continúe) más allá. 
constituye la tumba 24 , con una anilla de hierro, situada en la parte sur. De las tumbas con cuchillos, la que presenta un emplazamiento menos periférico respecto al resto es la 155 , que es, precisamente la que nosotros consideramos más antigua. En su revisión de la necrópolis Castro sugiere la existencia de dos grupos de tumbas que representan a dos sectores socialmente diferenciados: uno de ellos correspondería a la zona central, con enterramientos protegidos por débiles muretes a modo de recintos envolventes de algunos osarios, y el otro a las tumbas con gran cantidad de metal (en términos relativos) y con cuchillos de hierro. No obstante, no se han podido establecer relaciones entre la distribución de las variantes cerámicas y la expresión de diferencias sociales (Ruiz Zapatero 1985: 170; Castro 1994: 125). Castro cree ver en la evidencia de la necrópolis la expresión de dos grupos sociales distintos que corresponderían a "redes de relaciones sociales de diversa índole" y que se manifestarían en las tumbas con estructuras pétreas y aquellas en las que se amortiza una gran cantidad de metal o cuchillos de hierro que connotan posición social y que correspondería a un sector de población que estaría bien posicionado en relación a la gestión de los intercambios (Castro 1994: 155). Ruiz Zapatero (2004: 320), por su parte, también atribuye algún tipo de preeminencia especial a las tumbas con cuchillos. No cabe duda de que, aunque difícil de precisar, existe una clara voluntad de diferenciación de las tumbas con cuchillos de hierro, no solo por la presencia de este metal nuevo y probablemente difícil de obtener, sino por el hecho singular de que aparezca como elemento único del ajuar, extremo que en cierto modo viene a realzar aún más el valor económico y simbólico que sin duda poseyeron.

\section{Agradecimientos}

Agradecemos a Jaume Massó, director del Museu Salvador Vilaseca de Reus, que, con su habitual eficacia y amabilidad, haya facilitado la autopsia de las piezas que aquí se presentan. Carmen Prats efectuó una nueva restauración de dos de los cuchillos y Raquel Piqué el examen de la madera preservada en sus enmangues. Raimon Graells dibujó a lápiz las piezas de las tumbas 116, 146 y 155 y los dos fragmentos sin contexto, dibujos que fueron terminados a tinta por Antoni Llussà, a quien agradecemos especialmente su amabilidad en la conclusión de su trabajo. Todas estas tareas se realizaron en el marco del proyecto "El área minero-metalúrgica Molar-Bellmunt-Falset: contrastación de hipótesis" (HUM200765725-C03-01). Finalmente, agradecemos a dos revisores anónimos sus comentarios, que han contribuido a la mejora del texto.

\section{Bibliografía}

Almagro Basch, M. (1955): Las necrópolis de Ampurias. Diputación Provincial, Barcelona.

Almagro-Gorbea, M. (1977): El Pic dels Corbs, de Sagunto, y los Campos de Urnas del NE de la Península Ibérica. Saguntum, 12: 89-144.

Almagro-Gorbea, M. (1993): La introducción del Hierro en la Península Ibérica. Contactos precoloniales en el Período Protoorientalizante. Complutum, 4: 81-94.

Almagro-Gorbea, M.; Graells, R. (2011): Escarabeos del noreste de Hispania y del sur de la Galia. Catálogo, nuevos ejemplares e interpretaciones. Lucentum, 30: 25-87.

Almagro-Gorbea, M.; Lorrio, A. J. (2011): Teutates. El héroe fundador y el culto heroico al antepasado en Hispania y en la Keltiké. Bibliotheca Archaeologica Hispana, 36. Real Academia de la Historia, Madrid.

Alonso, N.; Junyent, E.; Lafuente, A.; López, J.B.; Tartera, E. (2000): La fortaleza de Arbeca. El proyecto Vilars 2000. Investigación, recuperación y socialización del conocimiento y del patrimonio. Trabajos de Prehistoria, 57(2): 161-173

Álvarez Sanchís, J. R.; Lorrio, A. J.; Ruiz Zapatero, G. (2016): Los primeros elementos de hierro en Iberia. Homenaje a la profesora Concepción Blasco Bosqued. Anejos a CuPAUAM, 2: 149-165.

Aquilué, X.; Castanyer, P.; Santos, M.; Tremoleda, J. (2008): Noves evidències del comerç fenici a les comunitats indígenas de l'entorn d'Empúries. Contactes: Indígenes i fenicis a la Mediterrània occidental entre els segles VIII $i$ VI ane (F. Gracia, D. Garcia, I. Moreno, eds.). Grup de Recerca en Arqueologia Protohistòrica, Barcelona: 171-190. 
Aquilué, X.; Castanyer, P.; Santos, M.; Tremoleda, J. (2012): El paisatge funerari en el territori d'Empúries, entre el Bronze Final i la primera edat del ferro. Les necròpolis d'incineració entre l'Ebre $i$ el Tíber (segles $I X-V I a C$ ): metodologia, pràctiques funeràries i societat (M. C. Rovira, F.J. López-Cachero, F. Mazière, dirs.). Monografies, 14. Museu d'Arqueologia de Catalunya, Barcelona: 75-90.

Armada, X.-L.; Hunt, M. A.; Juan, J.; Montero-Ruiz, I.; Rafel, N.; Ruiz de Arbulo, J. (2005): Primeros datos arqueométricos sobre la metalurgia del poblado y necrópolis de Calvari del Molar (Priorat, Tarragona). Trabajos de Prehistoria, 62(1): 139-155.

Arnold, B. (1993): The Material Culture of Social Structure: Rank and Status in Early Iron Age Europe. Harvard University 1991. Tesis Doctoral. Ann Arbor: University Microfilms International.

Aubet, M. E. (1975): La necrópolis de Setefilla en Lora del Río, Sevilla. Programa de Investigaciones Protohistóricas, II. CSIC-Universidad de Barcelona, Barcelona.

Barceló, J. A. (2008): La seqüència crono-cultural de la prehistòria catalana. Anàlisi estadística de les datacions radiomètriques de l'inici de l'Holocè a l'edat del ferro. Cypsela, 17: 65-88.

Blech, M. (1986): Las armas de la sepultura 155 de la necrópolis de Baza. Estudios de Iconografía II. Coloquio sobre el Puteal de la Moncloa. Catálogos y Monografías, 10. Museo Arqueológico Nacional, Madrid: 205-209.

Brandherm, D.; Krueger, M. (2017): Primeras determinaciones radiocarbónicas de la necrópolis de Setefilla (Lora del Río) y el inicio del periodo orientalizante en Andalucía occidental. Trabajos de Prehistoria, 74(2): 296-318.

Bronk Ramsey, C. (2009): Bayesian analysis of radiocarbon dates. Radiocarbon, 51(1): 337-360.

Castro, P. V. (1994). La sociedad de los Campos de Urnas en el nordeste de la Península Ibérica. La necrópolis de El Calvari (El Molar, Priorat, Tarragona). BAR International Series, 592. BAR Publishing, Oxford.

Clop, X.; Faura, J.-M.; Gandonells, M.; Molist, M.; Navarro, C. (1998): El Pla de la Bruguera. Centre de distribució Sony. Una necròpolis d'incineració de la Primera Edat del Ferro a Castellar del Vallès (Castellar del Vallès, Vallès Occidental). Excavacions Arqueològiques a Catalunya, 15. Departament de Cultura - Generalitat de Catalunya, Barcelona

Filippini, A. (2007): Les couteaux en fer du sud-ouest de la Gaule (VIII'-Ve s. a.C.). L'économie du fer protohistorique: de la production à la consommation du métal. XXVIII colloque de l'AFEAF, Toulouse, 20-23 mai 2004 (P.-Y. Milcent, dir.). Aquitania, suppl. 14/2, Bordeaux: 395-405.

Garrido, J. P. (1970): Excavaciones en la necrópolis de "La Joya", Huelva (1 ${ }^{a}$ y $2^{a}$ campañas). Excavaciones Arqueológicas en España, 71. Ministerio de Educación y Ciencia. Dirección General de Bellas Artes. Comisaria General de Excavaciones Arqueológicas, Madrid.

Gener, M.; Rovira, S.; Montero-Ruiz, I.; Renzi, M.; Rafel, N.; Armada, X.-L. (2007): Análisis de escorias de plomo del poblado de la Edad del Hierro de El Calvari en El Molar (Priorat, Tarragona). Avances en Arqueometría 2005. Actas del VI Congreso Ibérico de Arqueometría (J. Molera, J. Farjas, P. Roura, T. Pradell, eds.). Universitat de Girona, Girona: 153-161.

Gómez-Paccard, M.; Rivero-Montero, M.; Chauvin, A.; García i Rubert, D.; Palencia-Ortas, A. (2019): Revisiting the chronology of the Early Iron Age in the north-eastern Iberian Peninsula. Archaeological and Anthropological Sciences, 11: 4755-4767.

Gómez Ramos, P. (1996): Análisis de escorias férreas: nuevas aportaciones al conocimiento de la siderurgia prerromana en España. Trabajos de Prehistoria, 53: 145-155.

González, J. R.; Vàzquez, M. P.; Mata, J. M.; Peña, J. L.; Rodríguez, J. I.; Colldeforns, B. (2002): La presencia de hematites y la singular concentración de poblamiento de la primera Edad del Hierro en la confluencia de los ríos Cinca, Segre y Ebro. Primer Simposio sobre la Minería y la Metalurgia Antigua en el SW Europeo (J. M. Mata, J. R. González, coords.). Centre d'Arqueologia d'Avinganya, Serós: 233-254.

Graells, R. (2010): Las tumbas con importaciones y la recepción del Mediterráneo en el Nordeste de la Península Ibérica (siglos VII-VI a.C.). Revista d'Arqueologia de Ponent, Número Extra. Universitat de Lleida, Lleida.

Grevey, A.-L.; Gailledrat, E. (2020): The origins of the first ferrous knives on the Iberian Peninsula and in Southern France: a typological viewpoint (9th-7th centuries BC). Iron Metallurgy and the Formation of Complex Societies in the Western Mediterranean (1st Millennium BC) (M. C. Belarte, M. C. Rovira, J. Sanmartí, eds.). ArqueoMediterrània, 15: 115-124. 
Janin, Th.; Chardenon, N. (1998): Les premiers objets en fer en Languedoc occidental et en Rousillon (VIIIe s. av. n. è.): types, chronologie et origine. Recherches sur l'économie du fer en Méditerranée nord-occidentale (M. Feugère, V. Serneels, dirs.). Monographies Instrumentum, 4. Ed. Monique Mergoil, Montagnac: 56-64.

Janin, Th.; Taffanel, O.; Taffanel, J. (1998): La nécropole du Moulin à Mailhac (Aude). Monographies d'Archéologie Méditerranéenne. Association pour la Recherche Archéologique en Languedoc Oriental (ARALO).

Jockenhövel, A. (1980): Die Rasiermesser in Westeuropa (Westdeutschland, Niederlande, Belgien, Luxemburg, Frankreich, Großbritannien und Irland). Prähistorische Bronzefunde, 8(3). Beck, München.

Junyent, E. (1992): Els orígens del ferro a Catalunya. Revista d'Arqueologia de Ponent, 2: 21-35.

Junyent, E. (2002): Els segles de formació: el bronze final i la primera edat del ferro a la depressió de l'Ebre. I Jornades d'Arqueologia Ibers a l'Ebre. Recerca i interpretació, Tivissa, 23-24 de noviembre 2001. Ilercavònia, 3: 17-35.

López Cachero, F. J. (2005): La necrópolis de Can Piteu-Can Roqueta (Sabadell) en el contexto del Bronce Final y Primera Edad del Hierro en el Vallés. 2 vols. Tesis Doctoral. Universitat de Barcelona, Barcelona. http://hdl.handle.net/2445/42623

López-Cachero, F. J.; Pons, E. (2008): La periodització del bronze final al ferro inicial a Catalunya. Cypsela, 17: 51-64.

López-Cachero, F. J.; Rovira-Hortalà, M. C. (2008): First iron knives in Western Mediterranean between 8th and 6th centuries BC: The Can Piteu - Can Roqueta (Sabadell, Spain) foundings. Early Iron in Europe. Prehistoric, Roman and Medieval Iron Production. International Conference, Hüttenberg, Carinthia, Austria, $8^{\text {th }}-12^{\text {th }}$ September 2008. Abstracts (B. Cech, ed.): 89.

López Cachero, F. J.; Rovira, M. C.; Carlús, X.; Lara, C.; Villena, N. (2009): Nouvelles données concernant la transition entre le Bronze final et le Premier âge du Fer en Catalogne côtière. La nécropole à incinération de Can Piteu-Can Roqueta (Barcelone, Espagne). De l'âge du Bronze à l'âge du Fer en France et en Europe occidentale (Xe-VIIe siècle av. J.-C.). La moyenne vallée du Rhône. Actes du XXXe colloque international de l'AFEAF, co-organisé avec l'APRAB (Saint-Romain-en-Gal, $26-28$ mai 2006) (M.-J. Roulière-Lambert, A. Daubigney, P.-Y. Milcent, M. Talon, J. Vital, eds.). Revue Archéologique de l'Est 27 y Supplément, Dijon: 213-225.

López Cachero, F. J.; Rovira, M. C. (2012): El món funerari a la depressió prelitoral catalana entre el bronze final i la primera edat del ferro: ritual i dinamisme social a partir del registre arqueològic. Les necrópolis d'incineració entre l'Ebre i el Tíber (segles IX-VI a.C.) (M. C. Rovira, F. J. López Cachero, F. Mazière, eds.). Monografies del Museu d'Arqueologia de Catalunya-Barcelona 14, Barcelona: 37-55.

Lorrio, A. J. (2008): Cuchillos. La necrópolis de Medellín. II. Estudio de los hallazgos (M. Almagro-Gorbea, A. J. Lorrio, A. Mederos, M. Torres). Bibliotheca Archaeologica Hispanica, 26(2). Real Academia de la Historia, Madrid: 566-571.

Louis, M.; Taffanel, O; Taffanel, J. (1958): Le premiar Àge du Fer languedocien. 2ème. partie: Les nécropoles à incinération. Institut International d'Études Ligures, Bordighera-Montpellier.

Mancebo, J. (2000): Análisis de objetos metálicos en el período orientalizante y su conexión con el mundo fenicio. Los cuchillos afalcatados. Actas del IV Congreso de Estudios Fenicios y Púnicos. Cádiz 1995 (vol. IV). Universidad de Cádiz, Cádiz: 1825-1834.

Mateos Leal, C. M.; Sánchez Nicolás, D. (2014): El cuchillo afalcatado. Análisis tipológico y funcional de los cuchillos de los yacimientos abulenses durante la II Edad del Hierro. Investigaciones arqueológicas en el valle del Duero. Del Paleolítico a la Antigüedad Tardía. Actas de las III Jornadas de Jóvenes Investigadores del Valle del Duero (F. J. González, E. Paniagua, P. de Inés, coords.). Glyphos, Valladolid: 135-150.

Montero-Ruiz, I.; Rafel, N.; Rovira, M. C.; Armada, X.-L.; Graells, R.; Hunt, M. A.; Murillo-Barroso, M.; Renzi, M.; Santos, M. (2012): El cobre de Linares (Jaén) como elemento vinculado al comercio fenicio en El Calvari de El Molar (Tarragona). Menga, 3: 167-184.

Nickels, A. (1989): Agde, la nécropole du premier âge du fer. Revue Archéologique de Narbonnaise, Suppl. 19. Editions du CNRS.

Nickels A.; Pellecuer, C.; Raynaud, C.; Roux, J.-C.; Adgé, M. (1981): La nécropole du Ire Âge du Fer d'Agde: les tombes à importations grecques. Mélanges de l'École Française de Rome. Antiquité, 93(1): 89-125. 
Núñez, F. J. (2015): Reflexiones sobre la cronología de los inicios de la Edad del Hierro en el Mediterráneo occidental y sus problemas. CuPAUAM, 41:23-37.

Olmos, R. (1986): Propuestas de paradigmas y vías de investigación. Estudios de Iconografía II. Coloquio sobre el Puteal de la Moncloa. Catálogos y Monografías, 10. Museo Arqueológico Nacional, Madrid: 183-186.

Padró, J. (1983): Egyptian-type documents from the mediterranean littoral of the Iberian Peninsula before the roman conquest, II. Study of the material: From Western Languedoc to Murcia. Brill, Leiden.

Pare, C. (2017): Frühes Eisen in Südeuropa: Die Ausbreitung einer technologischen Innovation am Übergang vom 2. zum 1. Jahrtausend v. Chr.). Das Nördliche Karpatenbecken in der Hallstattzeit. Wirtschaft, Handel und Kommunikation in früheisenzeitlichen Gesellschaften zwischen Ostalpen und Westpannonien (E. Jerem, ed.) Archaeolingua 38, Budapest: 11-116.

Pereira, J. (2008): Nuevos escenarios en el circuito de intercambios de época colonial: los vados del Tajo. Contactes: Indígenes i fenicis a la Mediterrània occidental entre els segles VIII $i$ VI ane (F. Gracia, D. Garcia, I. Moreno, eds.). Grup de Recerca en Arqueologia Protohistòrica, Barcelona: 191-209.

Pereira, J.; Ruiz Taboada, A.; Carrobles, J. (2003): Aportaciones del C-14 al mundo funerario carpetano: la necrópolis de Palomar de Pintado. Trabajos de Prehistoria, 60(2): 153-168.

Pita, R.; Díez-Coronel, L. (1968): La necrópolis de "Roques de San Formatge" en Seros (Lérida). Excavaciones Arqueológicas en España, 59. Ministerio de Educación y Ciencia, Madrid.

Plicht, J. van der; Bruins, H. J.; Nijboer, A. J. (2009): The Iron Age around the Mediterranean: a high chronology perspective from the Groningen Radiocarbon Database. Radiocarbon, 51(1): 213-242.

Pons, E. (1984): L'Empordà. De l'edat del bronze a l'edat del ferro., 1100-600 a.C. Centre d'Investigacions Arqueològiques de Girona, Girona.

Pons, E.; Solès, A. (2008): La necròpolis d'incineració del Pi de la Lliura-Vidreres. Ajuntament de Vidreres, Departament de Cultura de la Generalitat de Catalunya - MAC Girona, Vidreres-Girona.

Porra-Kouteni, V.; Dedet, B.; Marchand, G. (2010): Quand les morts témoignent des vivents. Des vases pour l'eternité. La nécropole de Negabous et la protohistoire du Roussillon (V. Porra-Kouteni, B. Dedet, G. Marchand, eds.). Conseil Général des Pyrénées-Orientales et Pole Archéologique Departamental, Perpignan: 74-89.

Rafel, N. (1991): La necròpolis del Coll del Moro de Gandesa. Els materials. Publicacions de la Diputació de Tarragona, Tarragona.

Rafel, N. (2007): El textil como indicador de género en el registro funerario ibérico. Interpreting household practices Barcelona, 21-24 november 2007. Treballs d'Arqueologia, 13: 115-146.

Rafel, N.; Armada, X.-L. (2008): Sobre la cronologia de la necròpolis del Calvari del Molar i l'horitzó funerari del bronze final i primera edat del ferro a l'Ebre. Noves datacions absolutes. Cypsela, 17: 149-159.

Rafel, N.; Montero-Ruiz, I.; Armada, X.-L.; Genera, M. (2021): Aprovechamiento e intercambio de metal: datos analíticos de piezas metálicas de los yacimientos protohistóricos tarraconenses de El Calvari (El Molar), La Tosseta (Els Guiamets) y El Puig Roig (El Masroig). Pyrenae, 52(2): 9-34.

Rafel, N.; Soriano, I.; Armada, X.-L.; Hunt, M. A.; Montero-Ruiz, I. (2019): Lead and copper mining in Priorat county (Tarragona, Spain): From cooperative exchange networks to colonial trade (2600-500 $\mathrm{BC}$ ). Metals, minds and mobility: Integrating scientific data with archaeological theory (X.-L. Armada, M. Murillo-Barroso, M. Charlton, eds.). Oxbow Books, Oxford and Philadelphia: 147-158.

Reimer, P.; Austin, W.; Bard, E.; Bayliss, A.; Blackwell, P.; Bronk Ramsey, C.; Butzin, M.; Cheng, H.; Edwards, R.; Friedrich, M.; Grootes, P.; Guilderson, T.; Hajdas, I.; Heaton, T.; Hogg, A.; Hughen, K.; Kromer, B.; Manning, S.; Muscheler, R.; Palmer, J.; Pearson, C.; Plicht, J. van der; Reimer, R.; Richards, D.; Scott, E.; Southon, J.; Turney, C.; Wacker, L.; Adolphi, F.; Büntgen, U.; Capano, M.; Fahrni, S.; Fogtmann-Schulz, A.; Friedrich, R.; Köhler, P.; Kudsk, S.; Miyake, F.; Olsen, J.; Reinig, F.; Sakamoto, M.; Sookdeo, A.; Talamo, S. (2020): The IntCal20 Northern Hemisphere radiocarbon age calibration curve (0-55 cal kBP). Radiocarbon, 62 (4): 725-757.

Renzi, M; Marzoli, D.; Suárez Padilla, J.; Bode, M. (2014): Estudio analítico de los materiales arqueometalúrgicos procedentes de Los Castillejos de Alcorrín (Manilva, Málaga). Yacimiento del Bronce Final/ Inicio de la Edad del Hierro en el entorno del Estrecho de Gibraltar. Madrider Mitteilungen, 55: 121166.

Renzi, M.; Rovira, S.; Rovira M. C.; Montero-Ruiz, I. (2013): Questioning research on early iron in the Mediterranean. The World of Iron (J. Humpfris, Th. Rehren, eds.). Archetype Publications, London: 178-187. 
Reverte, J. M. (1986): Informe antropológico y paleopatológico de los restos cremados de la Dama de Baza. Estudios de Iconografía II. Coloquio sobre el Puteal de la Moncloa. Catálogos y Monografías, 10. Museo Arqueológico Nacional, Madrid: 187-192.

Rovira, M. C. (1998): Les premiers objects en fer en Catalogne (VII ${ }^{\mathrm{e}}-\mathrm{VI}^{\mathrm{e}}$ s. a.v.n. ere). Recherches sur l'économie du fer en Méditerranée nord-occidentale (M. Feugère, V. Serneels, dirs.). Monographies Instrumentum, 4. Ed. Monique Mergoil, Montagnac: 45-55.

Rovira, M. C. (2004): Producción e intercambio de los primeros objetos de Hierro del nordeste de la Península Ibérica (S. VII-VI a.C.). L'économie du fer protohistorique: de la production à la consommation du métal. XXVIII colloque de l'AFEAF, Toulouse, 20-23 mai 2004 (P.-Y. Milcent, dir.). Aquitania, suppl. 14/2, Bordeaux: 167-175.

Rovira, M. C.; López-Cachero, F. J. (2016): Las fíbulas serpentiformes de Cataluña en el marco del Mediterráneo noroccidental. Vie quotidienne, tombes et símbols des sociétés protohistòriques de Mediterranée nord-occidental. Mélanges oferts à Bernard Dedet, 2 (Cl.-A. De Chazelles, M. Schwaller, eds.). Monographies d'Archéologie Méditerranéene, hors sèrie 7, Lattes: 705-719.

Rovira, S. (2000): Continuismo e innovación en la metalurgia ibérica. III Reunió sobre Economia en el Món Ibèric. Sagvntvm-PLAV, Extra-3: 209-221.

Ruiz-Gálvez, M. (1998): La Europa atlántica en la Edad del Bronce. Un viaje a las raíces de la Europa Occidental. Crítica, Barcelona.

Ruiz-Gálvez, M. (2005): Representaciones de barcos en el arte rupestre: piratas y comerciantes en el tránsito de la Edad del Bronce a la Edad del Hierro. Mayurqa, 30: 307-339.

Ruiz Mata, D.; Pérez, C. J. (1989): El túmulo 1 de la necrópolis de "Las Cumbres" (Puerto de Santa María, Cádiz). Tartessos. Arqueología Protohistórica del Bajo Guadalquivir (M. E. Aubet, coord.). Ausa, Sabadell: 287-295.

Ruiz Zapatero, G. (1985): Los Campos de Urnas del NE de la Península Ibérica. Ediciones de la Universidad Complutense, Madrid.

Ruiz Zapatero, G. (2004): Casas y tumbas. Explorando la desigualdad social en el Bronce Final y primera Edad del Hierro del NE. De la Península Ibérica. Mainake, 26: 293-330.

Solier, Y.; Rancoule, G.; Passelac, M. (1976): La nécropole de "las Peyros", VIe siècle av. J.C. à Couffoulens (Aude). Revue Archéologique de Narbonnaise, suppl. 6. Paris.

Subirà, M. E.; Rovira, M. C.; Ruiz, J.; Pons, E. (2012): La necrópolis d'incineració del Pi de la Lliura (Vidreres, Girona): una aproximació demográfica. Les necròpolis d'incineració entre l'Ebre i el Tíber (segles IX-VI aC): metodologia, pràctiques funeràries i societat (M. C. Rovira, F.J. López-Cachero, F. Mazière, dirs.). Monografies, 14. Museu d'Arqueologia de Catalunya, Barcelona: 145-151.

Tarrús, J.; Carreras, E. (2012): Els recintes megalítics del Mas Baleta-III (la Jonquera, Alt Empordà). Cypsela, 19: 123-139.

Toledo, A. (2008): La necrópolis de Can Bech de Baix, Agullana (Alt Empordà, Girona). Les necròpolis d'incineració entre l'Ebre $i$ el Tíber (segles $I X-V I$ aC): metodologia, pràctiques funeràries $i$ societat (M. C. Rovira, F.J. López-Cachero, F. Mazière, dirs.). Monografies, 14. Museu d'Arqueologia de Catalunya, Barcelona: 161-170.

Toledo, A.; Palol, P. (2006): La necrópolis d'incineració del Bronze Final transició a l'Edat del Ferro de Can Bech de Baix, Agullana (Alt Empordà, Girona). Els resultats de la campanya d'excavació de 1974. Sèrie Monogràfica, 24. Museu d'Arqueologia de Catalunya - Girona, Girona.

Vàzquez, M. P.; Medina, J.; González, J. R.; Rodríguez, J. I. (2006-07): El jaciment de la Serra del Calvari (la Granja d'Escarp, el Segrià, Lleida). Estat de la qüestió. Revista d'Arqueologia de Ponent, 16-17: 63-110.

Vilaça, R. (2006): Artefactos de ferro em contextos do Bronze Final do territorio português: novos contributos e reavaliação dos dados. Complutum, 17: 81-101.

Vilaseca, S. (1943): El poblado y necrópolis prehistóricos de Molá (Tarragona). Acta Arqueológica Hispánica, I. Ministerio de Educación Nacional - Comisaría General de Excavaciones Arqueológicas, Madrid.

Vilaseca, S. (1954): Nuevos yacimientos tarraconenses de cerámica acanalada. Instituto de Estudios Tarraconenses "Ramón Berenguer IV" - Centro Comarcal de Reus, Reus.

Vilaseca, S.; Solé, J. M.; Mañé, R. (1963): La necrópolis de Can Canyís (Banyeres, prov. de Tarragona). Trabajos de Prehistoria, 8. CSIC, Madrid. 
Weglian, E. (2001): Graves goods do not a gender make: a case study from Singen am Hohentwield, Germany. Gender and the Archaeology of Death (B. Arnold, N. L. Wicker, eds.). Altamira Press, Walnut Creek: $137-156$.

Zamora, T. (2014-15). Los cuchillos de hierro procedentes de las necrópolis de incineración catalanas (VIII-VI a.C.). Clasificación, funcionalidad y tecnología. El caso de Can Piteu-Can Roqueta. Trabajo de Fin de Grado. Universitat de Barcelona, Barcelona. < diposit.ub.edu/bitstream/2445/109852/1/TFG_Zamora Hinojosa_Tamara.pdf $>$ 